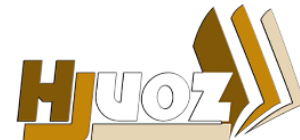

hjuoz.uoz.edu.krd p-ISSN: 2664-4673 e-ISSN: $2664-4681$
كوّوارا زانستيّن مروّقايهتى يا زانكوّيا زاخوّ

مجلة العلوم الانسانية لجامعة زاخو

Humanities Journal of University of Zakho (HJUOZ)

Vol. 7, No. 1, pp. 139-156, March.-2019

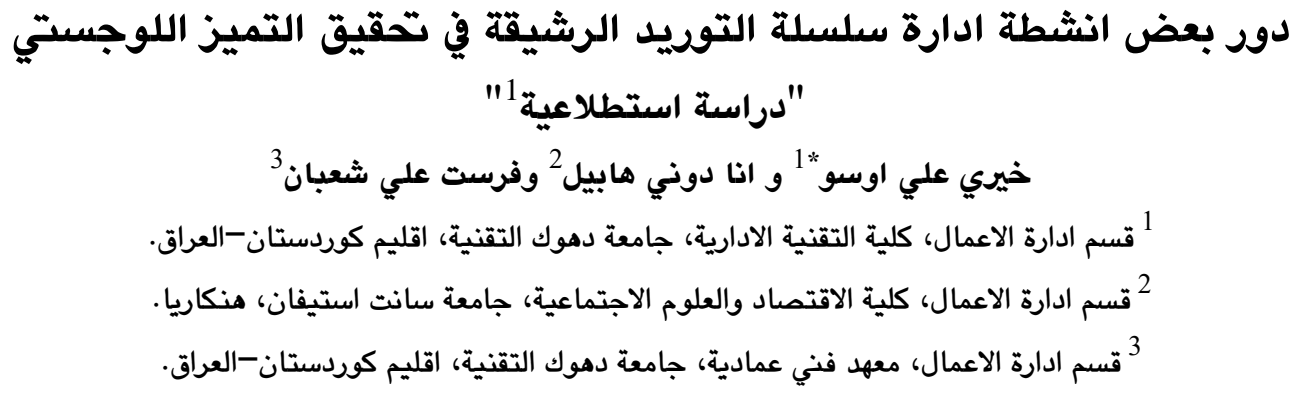

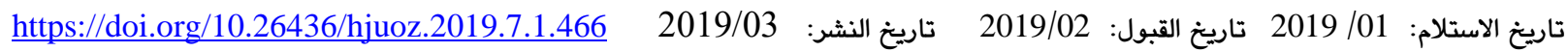

الملخص:

سعت الدراسة لتحديد العلاقة بين انشطة ادارة سلسلة التوريد الرشيقة متمثلة بالأنشطة (الشراء الرشيق والنقل الرشيق والتخزين الرشيق) في تحقيق التميز اللوجستي بالاعتماد على مجموعة فرضيات تنص على ان هذه الانشطة ترتبط وتؤثر في التميز اللوجستي، طبقت الدراسة على شركتين

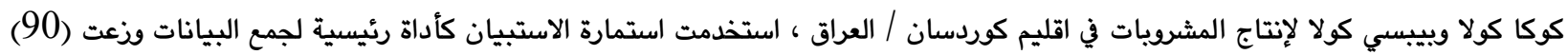
استمارة على مدراء سلاسل التوريد واللوجستيك ومدراء الخط الاول بلغ عدد استمارات الصالحة للتحليل (80) استمارة، استخدم اختبارات الارتباط والتأثير لتحقق من فرضيات الدراسة، نتائج التحليل الاحصائي دعمت فرضيات الدراسة ويينت وجود علاقات ارتباط وتأثير لأنشطة سلسلة التوريد الرشيقة في التميز اللوجستي واقترح الباحثين اجراء المزيد من الدراسات في المستقبل حول الموضوع لدعم وتعزيز نتائج هذه الدراسة. مساهمة

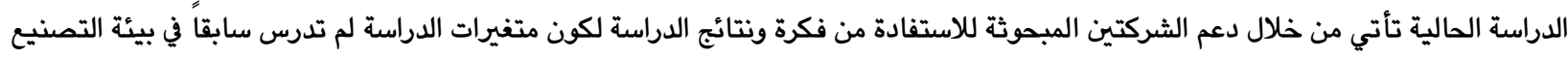

Lean Supply Chain Management LSCM كنهج إداري فعال يساعد في القضاء على الهدر وتقليل التكاليف وتحقيق قيمة أفضل للزيون وسيلة لتحقيق الميزة التنافسية (Sezen \& Erdogan , 2009, 68). ومن خلال اطلاع الباحثين وجدوا بان هناك العديد من الدراسات ناقشت العلاقة بين انشطة LSCM مع المتغيرات الاخرى منها: كلفة وجودة

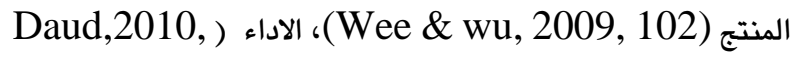
(5; Nimeh et al ., 2017, 12 (Al-Tit, Wachuma et al., 2016, 43) Oko, 2016, ) 2016, 2) 2073)، تحسين سلسلة التوريد (Czarnecka et al., $.2017,19)$

ولم يعثر الباحثين على دراسة تربط انشطة LSCM والتميز

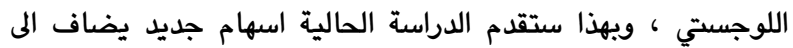

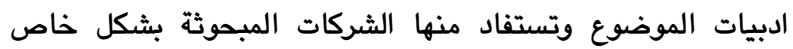

الكلمات الدالة: الرثاقة ، سلسلة التوريد ، التميز اللوجستي.

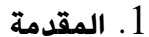

يدرك مدراء المنظمات ان الاعتماد على انشطة ادارة سلسلة التوريد Supply chain Management SCM في عصرنا الحالي تعني استنزاف للموارد وخسارةً للزبائن وللحصة السوقية فالتغيرات الهائلة في عالم الاعمال نتيجة لتطور تكنولوجيا الانتاج والاتصالات والمنافسة الشديدة أضلت بتأثيرها على SCM والانشطة اللوجستية التي تتضمنها فقامت العديد من المنظمات بالبحث عن ممارسات وطرق حديثة تلائم متطلبات العصر.

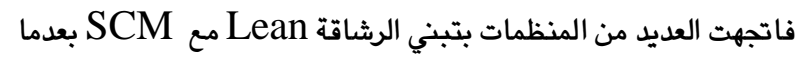
تبين امكانية اعتماده معه (Slack et al., 2010,33). وما بعام شجعت المنظمات لتبني المفهوم بشكل اكبر الفوائد والمزايا التي يحقهها متمثلة بتقليل الكلف وتحسين جودة المنتجات وتحسين جودة خدمة الزيون (Cudney \& Elrod, 2011,22). وتقديم دعم

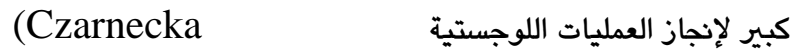
et al., 2017, 76) 
3. ما طبيعة العلاقة والأثر بين أنشـــــ LSCM وتحقيق التميز اللوجستي في الشركتين المبحوثتين ؟

2.2 - 2. أهمية الدراسة:

تأتي اممية الدراســـة من خلال طبيعة ابعادها المدروســـة نظرياً وما

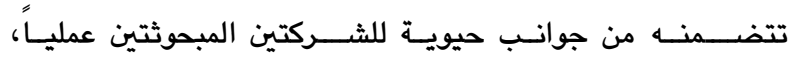
فسلاسل التوريد الرشيقة بفلسفتها المستندة على معالجة الهدر اصبح واقعاً الزاميا اوجدته معالم وتوجهات العصــر الحالي للزبائن الباحثين على القيمة وتعظيمها، بالإضــــافة لدورها في تحقيق متطلبات التميز اللوجســتي المفهوم الحديث المهم الذي تأخذ اهتمامات واســـة لدى مدراء الانتاج وسلاسل التوريد واللوجستيك.

3.2. - أهداف الدراسة:

تهدف الدراســة لتقديم إطار فكري مســندة على مجموعة افكار لجعل الشـركتين المبحوثتين قادرة على اسـتيعاب مفهوم LSCM ليكون

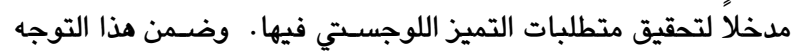

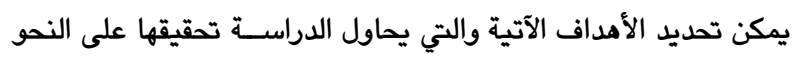
الآتي: 1. توضــيح أنثـــــ LSCM ومتطلبات تنفيذها, وتحديد أهم المقومات والمشكلات التي تواجه تحقيقها. 2. توضــيح مفهوم التميز اللوجســـي وتحديد متطلبات تحقيقها

والمشكلات التي تواجه تحقيقها.

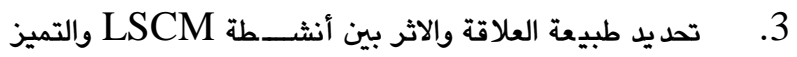
اللوجستي في الشركتين المبحوثتين.

4.2. المخطط الافتراضي للدراسة:

لتحقيق اهداف الدراسة وييان مشكلتها يتطلب بناء مخطط افتراضي معتمداً في تركيبها على ابعاد الدراسة ومتغيراتها الاساسية بحيث تسهر في توضيح علاقات والاثر بينهما ويكون تمهيداً لصياغة فرضيات

الدراسة.
والشركات الاخرى العاملة في العراق وستتبنى الدراسة فرضياتها من خلال طرح السؤال الاتي: مل تسهم انشطة LSCM في تدقيق التميز اللوجستي في الشركتين المجحوثتين ؟. واستناداً الى الطرح السابق ستتضمن الدراسة المحاور الاتية: المحور الأول: منهجية الدراسة المحور الثاني: الاطار النظري المحور الثالث: الإطار العملي / قياس وتحليل النتائج واختبار فرضياتها المحور الرابع: الاستنتاجات والمقترحات.

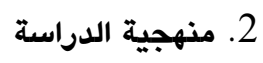

1.2 1.2

تشير الدراسات بان الشركات الانتاجية في العراق تعاني من مشاكل

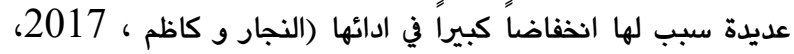
3). أما الخدمات اللوجستية فأنها ليست على افضل حال ايضاً نتائج تقرير (World Bank , 2014,37) اشار بان جودة الخدمة اللوجستية للشركات العاملة في العراق ليس بالمستوى المطلوب. هذه الحقائق والمؤشرات اخذتها الشركات العاملة في اقليم كوردستان العراق بشكل جدي ويدأت تبحث عن الطرق والاساليب اللازمة لتحسين ادائها وخاصة في سلاسل توريدما وانشطتها اللوجستية، وجاءت مذه الدراسة للمساعدة في تحقيق هذا الهدف بعدما تأكد الباحثين بعدم وجود دراسات سابقة درست العلاقة بين انشطة LSCM والتميز اللوجستي في بيئة تصنيع المحلية، وتتضح معالم مشكلة الدراسة بشكل اوضح من خلال طرح مجموعة من الاسئلة التي تحاكي السؤال الرئيس للدراسة 1. مل لدى العاملين في الشـركتين المبحوثتين فكرة عن LSCM وطبيعة أنشطتها ؟ 2. مل تســهم أنثـــة LSCM في تحقيق التميز اللوجسـتي في

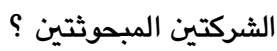

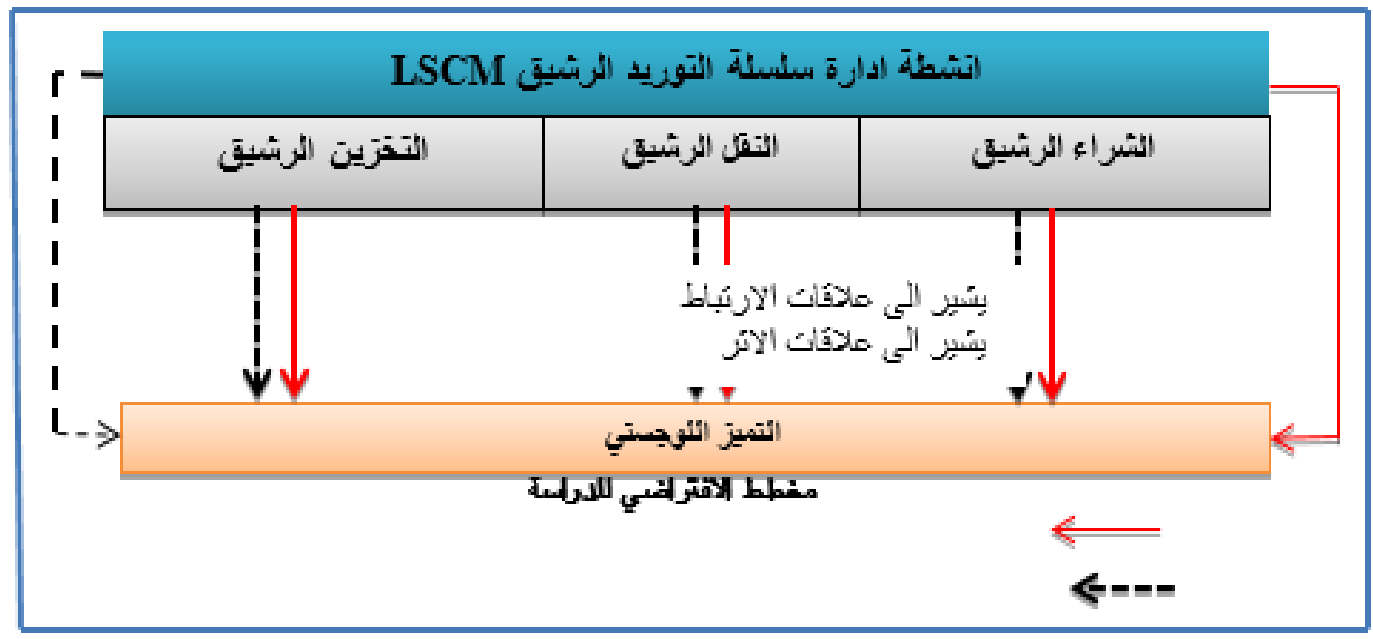

المصدر: من إعداد الباحثين 
وصــف اسـتمارة الاسـتبانة: اعتمد الباحثين في قياس اسـتجابة المبحوثين على مقياس (Likert) الخماسـي الوزن لكونه الانســبـ للدراســـة الحالية بحســبـ راي الخبراء، ورتبت درجات المقياس من

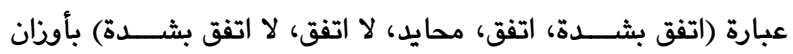

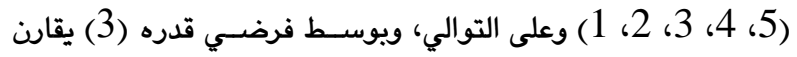

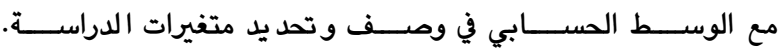
واشتملت استمارة الاستبانة على الاجزاء الاتية: الجزء الأول: يتضمن بيانات خاصة عن المبحوثين وتشمل (الجنس, العمر, مدة الخدمة في الشركة, التحصيل الدراسي، المركز الوظيفي, عدد الدورات والمؤتمرات في مجال سلسلة التوريد واللوجستيك).

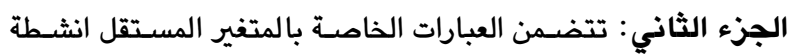
LSCM (Hagstrom \& Wollner, 2011) ; (Oko, الكتـاب

$$
\text { : 2016) }
$$

(Taylor \& Martichenko ,2006); ( Johansson, 2010) ;(Arriaga , et al ., 2013); (Thuranira,2016 ) .

التخزين الرشــيق: (Tostar, 2008);(Myerson, 2008); (Bozer, 2012 ); (de Visser, 2014); (Swart, (2015. ويلغ عدد عبارات كل نشــاط (8) ) ، مجموعها بلغ (24) (2012)

الجزء الثالث: تتضـــمن العبارات الخاصـــة بالمتغير المعتمد التميز

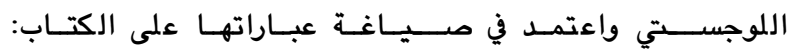
(Wirtz et al ., 2008); (Groznik \& Xiong, 2012);

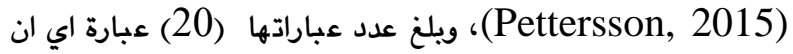
مجموع عبارات الاستبيان بلغ (44) عبارة.

7.2 الأساليب الإحصائية المستخدمة:

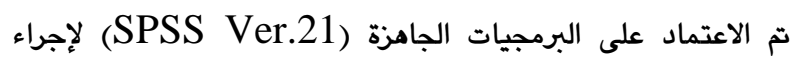
التحليل الإحصائي من خلال ايجاد القيم الاتية: أ - التكرارات : لاستعراض الاجابات الخاصة بالمبحوثين . ب- النســب المئوية : لبيان نســبة اجابة المبحوثين عن متغير معين

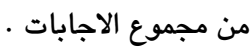
ت- الوسـط الحسـابي: لعرض متوسـط اجابات المبحوثين عن متغير مeمين

ث- الانحراف المعياري: لتحديد تشتت اجابات المبحوثين عن وسطها

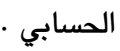
ج- نســـبة الاســتجابة: لتحديد إســـــابة المبحوثين ومواقفهم إزاء متغيرات الدراسة .

وتد سب وفق الصيغة الاتية: ذسبة الاستجابة الى مـاحة المقياس= (الوسط الحسابي / مساحة المقياس) × 100

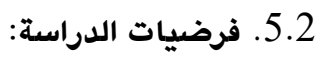

لاختبار العلاقات الموضـــة في مخطط الافتراضــي للدراســــ والتعرف على امكانية حل مشكلتها من عدمها حُددت الدراسة الفرضيات الاتية

1.5.2. توجد علاقة ارتباط معنوية بين أنشطة LSCM مجتمعة

$$
\text { والتميز اللوجستي. }
$$

2.5.2. توجد علاقة ارتباط معنوية بين أنشطة LSCM منفردة

$$
\text { والتميز اللوجستي. }
$$

3.5.2. يوجد تأثير معنوي لأنشطة LSCM مجتمعة في التميز

$$
\text { اللوجستي. }
$$

4.5.2. يوجد تأثير معنوي لأنشطة LSCM منفردة في التميز

5.5.2. أدوات جمع البيانات: بغية إعداد الدراسة بالشكل التي يحقق اهدافها واختبار مخططها تم الاستعانة بالعديد من البيانات والمعلومات الضرورية والهامة، ويمكن تأشير احتياجات الدراسة للبيانات والمعلومات على جانبين : 1. الجانب النظري: تم تنظيم وكتابة الجانب النظري للدراسة بالاعتماد على المراجع والدوريات والتقارير والدراسات الجامعية من

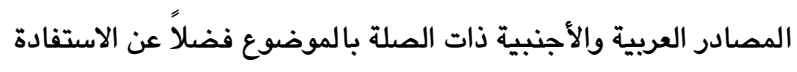
من خدمات شبكة المعلومات الدولية (الانترنيت). 2. الجانب الميداني: التشخيص الدقيق والسليم للميدان المبحوث يتطلب اعتماد مجموعة من الادوات المناسبة لقياس الظاهرة والحصول على النتائج الدقيقة، ولقد اعتمدت الدراسة على عدة أدوات بحثية وهي: أ. المقابلات الشخصية: من خلال مقابلة ومحاورة والاستماع لآراء العديد من افراد عينة الدراسة الذين لديهم تأثير في قرارات متعلقة بسلسلة التوريد والانثطة اللوجستية. ب. الزيارات الميدانية: من خلال زيارة للميدان المبحوث بين الفترات (1/ / 2017) الى (1/ 6 / 2018) للتعرف على طبيعة الانشطة التي تمارسها والإجراءات التي تتخذها بصدد كل نشاط. ت. استمارة الاستبانة: أعتمد الدراسة استمارة الاستبانة كأداةً رئيسة لجمع البيانات وقياس متغيرات الدراسة والموضحة في الملحق (1)، وصممت بعناية لتكون ملائمة لقياس متغيرات الدراسة ومنسجمه مع بيئة وافراد الميدان المبحوث من حيث إدراكها وفهمها. وتم بناء

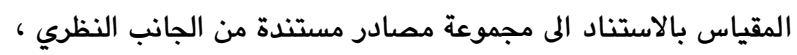
وتم عرضها على عدد من الخبراء المختصين، للتأكد من صحة الفقرات ومدى ملائمتها لفرضيات الدراسة وأهدافها وذلك لعدم تمكن الباحثين من ايجاد مقياس جاهز يمكن اعتماده لقياس الظاهرة قيد الدراسة. 6.2. وصف استمارة الاستبيان: 
كوكا كولا وييبسـي كولا للمشـرويات في محافظة اربيل وتم اختيارهما لمجموعة من المســـوغات اهمها امتلاكهما لحصـــة ســـوقية كبيرة في الاقليم ومحاولتها لتحســـن من اداء ســلاســل توريدها وانشــــــها اللوجستية ، وتم اختيار الأفراد العاملين في الشركتين المبحوثتين من الإدارة العليا والمدراء ومعاونيهم من الاقســــام والوحدات الذين لديهم علاقة بإدارة سـلســلة التوريد واللوجسـتيك وكان الدافع لاختيار مذه وماه الفئة كونها الأكثر قرباً لاتخاذ القرار وإدراكا لأبعاد ومتغيرات الدراسة.

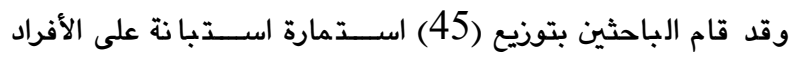
المبحوثين لكل شركة، استرجعت شركة كوكا كولا (42) وكانت عدد (2) استمارة غير صالحة للتحليل بسبب نقص البيانات والمعلومات، واسـترجعت شـركة بيبسـي كولا (40) اســمارة وجميعها صــالحة للتحليل.

10.2 10.2 يوضح الشكل (2) سمات افراد عينة الدراسة وابرز النقاط التي يمكن التركيز عليها هو ان نسـبة الذكور عالية جدا ، وتركزت اعمارهم حول سـن (25-45) ســنة وهي الاعمال تمتاز بالإنتاجية العالية واكثرهم ممن لديهم شهادة البكالوريوس وهو مؤشر جيد يعطي مصداقية اكثر لفهم واستيعاب فقرات الاستبيان.
ح- معامل الاختلاف: ويســتخدم لتحديد مســتوى إنســـام إجابات المبحوثين إِزاء متغيرات الدراســـة. ويحســبـ بالطريقة الاتية: معامل الاختلاف = (الانحراف المعياري / الوسط الحسابي) × 100 خ- معامل الارتباط: ويســتخدم لتحديد طبيعة العلاقة بين متغيرات الدراسة وتحديد قوتها التفسيرية. 3. معامل التأثير: لتحديد مدى تأثير متغير المســــقل على متغير المعتمد.

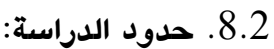

1- الحدود المكانية: اقتصــرت الدراســة على ثــركتي كوكاكولا وشركة بيبسي كولا للمشرويات في اقليم كوردستان- العراق.

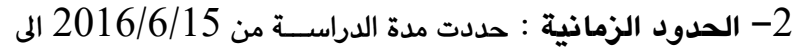
.2018/6/15 3. الحدود البشـــــية: تم اختيار الأفراد العاملين في الشـــركتين المبحوثتين من الإدارة العليا والمدراء ومعاونيهم من الاقسام والوحدات (الادارية ،الإنتاج، التســـويق والمبيـعات، المشـــتر يات، المخانن، اللوجستيك، المالية ، ضمان الجودة ، نظام المعلومات ). 9.2 سعى الباحثين لاختيار الميدان الانسب والذي يمكن أن يبين متغيرات وأهداف ومشكلة الدرا سة من خلاله، لذلك وقع الاختيار على شركتين

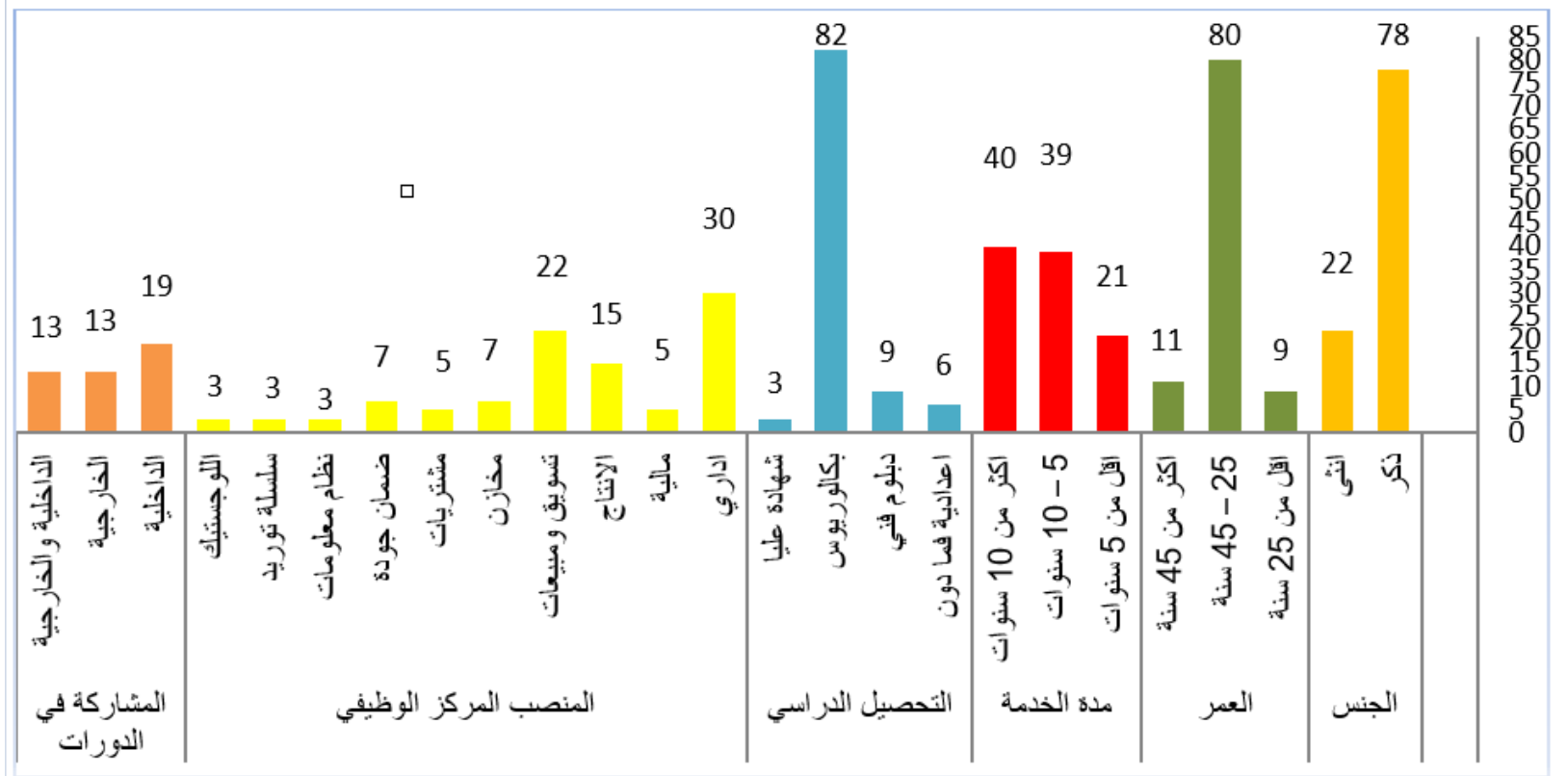

الشكل 2: سمات افراد عينة الدراسة

المصدر : من اعداد الباحثين

استخدام مفهوم الرثاقة مع SCM فكرتها جاءت عبر بحوث مركز أبحاث المشاريع الرشيقة في جامعة كارديف عام (1993) (Womack (Ugochukwu ,2012, 33). وافكار الكتاب)
3. الاطار النظري

1.3 ادارة سلسلة التوريد الرشيقة: 
الشراء الرشيق على المعرفة وادراك ما يريده الزبون ونقل حاجاته ورغباته بشكل صحيح الى الموردين لتشخيصها وتوفيرها بشكل

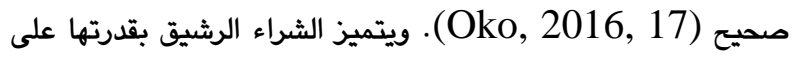
تقليل الكلفة والاسعار عبر بناء العلاقة الجديدة مع الموردين (wilson \& Roy,2009, 818). ولجعل نشاط الشراء رشيقاً يتطلب الالتزام بمجموعة ممارسات هذه الممارسات هي : التحسين المستمر، العلاقة مع الموردين، العلاقة مع الزبائن ، التوريد في الوقت المناسب JIT ، تزامن جداول الانتاج مع وظيفة اللوجستيات، جودة الادوات، مطية التغليف، السيطرة على شبكة اللوجستيات

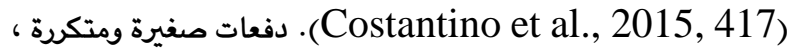
العلاقة مع الموردين وتحديد كيفية التسليم والوقت والمكان

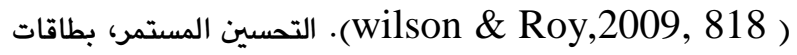
كنبان، العلاقة مع الموردين وتطويرها \& \&agstrom \& ) (Wollner, 2011, 5) الشراء الالكتروني، نظام السحب، ادارة الجودة الشاملة TQM، مشاركة العاملين، تنظيم موقع العمل 5S ، واوضحت الدراسة بان هذه نهاء الممارسات تقلل اوقات الانتظار والتكاليف، وتحسن من ادارة الطلب (Macharia, 2015, وجودة الخدمة المقدمة، وتحقق رضا الزبون

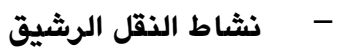

يرتبط نشاط النقل بالقيمة والزبائن، وتتعامل المنظمات مع هذا النشاط لتراط

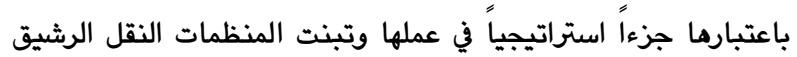

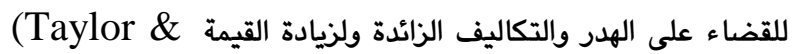
(Thuranira,2016, ويؤكد. Martichenko ,2006, 3) (15 الراي السابق ان العديد من المنظمات تبنت النقل الرشيق لمعرفتهم بالقيمة التي يضيفها وقدرتها على التخلص من الهدر التي لا تخلو اي نشاط نقل منه · ويرى (Arriaga et al ., 2013,8) بان النقل الرشيق بمثابة توجه استراتيجي موجه نحو القضاء على

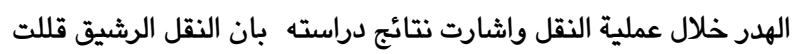
من وقت الدورة بنسبة (46\% )، عدد الطرق بنسبة (35\%)، تخفيض بال خسارة التعبئة بنسبة (60\%) ، ومذا ما يقلل من التكاليف الكلية

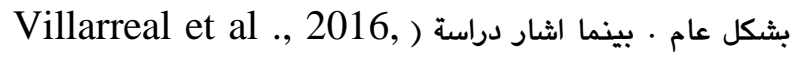

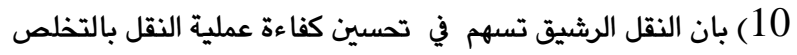
من الهدر في عملية النقل مثل اوقات الانتظار، الخدمات التي لا تضيف قيمة ، المسافات الزائدة . أما دراسة ( Hezbon ,2016,27) فبينت بان النقل الرثيق يسهم بشكل كبير في تسليم المواد والمنتجات للزبائن في الوقت المحدد مما يعزن من تحسين خدمة الزبون. وممارسات النقل الرثيق هي : الوسائط المتعددة Intermodal ، 5S ، فرق

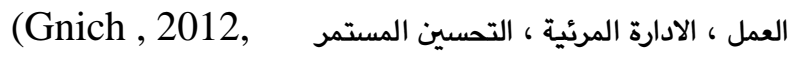
Villarreal et al., 2012, القضاء على الهدر ، JIT .24)
(Rossini \& (التفكير الرشيق) (في كتابهم and Jones) .Studacher, 2015, 3732)

ويتمحور فكرة مفهوم LSGM بتقليل او التخلص من الهدر والانشطة التي لا تضيف القيمة وتقليل الكلف وتحسين خدمة الزبون. فيعرف مفهوم LSGMansson,2010, 17) لإزالة وتقليل الأنثطة التي لا تضيف قيمة والهدر على طول سلسلة التوريد. اما (Daud \& Zailani, 2011, 5) فيرى بانها توظيف جهود التحسين المستمر للقضاء على جميع انواع الهدر والانشطة التي (Agus \& Hajinoor, لا تضيف قيمة. وفي السياق نفسه اشار 2012, 22) بانها مجموعة ادوات واساليب تهدف للقضاء على الهدر Afonso \& Cabrita ) ويشكل مستمر في سلسلة التوريد. ويتفق وانهات (Meera \& Chitramani ,2015, 67) ; , 2015, 270 على انه استراتيجية تستخدمه المنظمات لتقليل الكلف والاوقات وتحسين الكفاءة. ويعزز (Rachid et al ., 2017) الآراء السابقة ويشير بانها عملية القضاء على جميع انواع الهدر لزيادة تدفق سلسلة التوريد لتلبية احتياجات الزبائن الفورية. ومن المعروف بان SCM عبارة عن ترابط بين مجموعة من الانشطة Al-

(Slack et al., 2010, 457) Aomar \& Weriakat ,2012, , 295) فهي اصلاً انشطة SCMCM ولكن يتم التعبير عنها بأنشطة الرثيقة عند تبني مبادئ ممارسات وتقنيات الرثاقة فيها (Ugochukwu , 2012). والعديد من الكتاب امثال (Daud,2010; Tompkins, 2010; Al-Aomar \& Weriakat, 2012 ; Farah,2015) يرون بان انشطة LSCM هي: المورد الرشيق والشراء الرشيق والنقل الرشيق والانتاج الرشيق والتخزين الرشيق والزيون الرشيق. وستتناول هذه الدراسة الانشطة الشراء الرشيق والنقل الرشيق والتخزين الرشيق لكون هذه الانشطة بالاستناد على مبادئ وممارسات والتقنيات الرثيقة الاكثر تطبيقاً لدى الشركتين المبحوثتين. - - - - نشاط الشراء الرشيق يعد الشراء احدى الانشطة الداعمة التي اشار اليها Porter في سلسلة القيمة ودمجت في SCM لتحسين من اجراءاتها الادارية Hagstrom \& Wollner, 2011, 4) الشراء على نسبة عالية من التكاليف الكلية للمنظمة ففي الصناعات التحويلية (60- 70\%) من التكلفة الإجمالية للمنتج تذهب الم تكلفة (Reddy et شراء المواد الخام فجاء الاهتمام الكبير بمفهوم الشراء الرشيق al,. 2016, 291) لمعالجة مشكلة ارتفاع تكاليف الشراء ولمواجهة تحديات تقلبات الاسواق وقصر دورة حياة المنتج وتنبؤات الخاطئة وتزايد حاجات

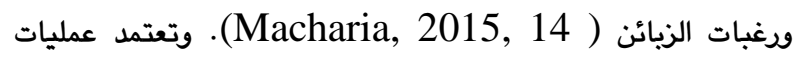


تبحث عن كيفية تحقيق التميز في انشطتها اللوجستية لاستخدامها كمصدر لتحقيق الميزة تنافسية (2015, Niemeyer, 2015

(Glatzel

واعتبر (إدريس، 2006) بان التميز اللوجستي الغاية العامة التي يجب

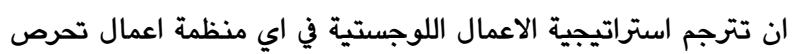
على تحقيق الميزة التنافسية في السوق ، ويتمثل مجال التركيز الاساسي للتميز اللوجستي في تدقيق مستويات عالية من الجودة والانتاجية لهذا النوع من الخدمات اللوجستية في المنظمة ويعرف التميز اللوجستي بانها " القدرة على انجاز المستويات العليا لجودة وانتاجية الاعمال اللوجستية ". وعرف (Cecere \& Mayer, 2013) (11 التميز اللوجستي بأنه " تحقيق أدنى تكلفة عند القيام بممارسة

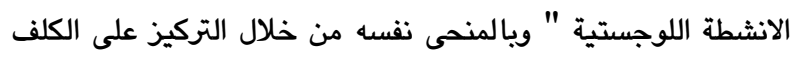
اللوجستية كأساس للتعبير عن مفهوم التميز اللوجستي يعرف التميز اللوجستي بانه "تحقيق الكفاءة (ARC, 2014, 7) والفاعلية تدفق السلع والخدمات والمعلومات عبر القنوات المتعددة والتي تربط جميع الاطراف من المنتجين الى الزبائن وياقل كلفة ". وفي سياق نفسه ربط (شعيب، 2014، 95) بين الجودة والكلف كأساس لتوضيح مفهوم التميز اللوجستي وتحقيقه وعرف التميز اللوجستي بانه " مفهوم يعبر عن تقديم الخدمات اللوجستية بأفضل جودة ويأقل كلفة وفي الوقت المناسب " وان التميز اللوجستي مفهوم يقوم بربط الانتاج والجودة معاً وهو اساس محدد لاستمرار تحقيق الهدف الاسمى

للخدمات اللوجستية.

والسؤال التي يطرح نفسه الان هو : كيف ستحقق المنظمة التميز اللوجستي؟ من خلال الطرح السابق ويعد اطلاع الباحثين على ادبيات الموضوع يمكن تحديد اهم المجالات التي يمكن ان تساهم في تحقيق

$$
\text { التميز اللوجستي }
$$

1. التركيز على الزبون

التركيز على الزبون وفهم متطلباته يسهم في تحسين جودة الخدمة اللوجستية ويعز من القيمة المكانية والزمانية للخدمة اللوجستية المقدمة وهو طريق لتحقيق التميز اللوجستي ( Mentzer et al.,

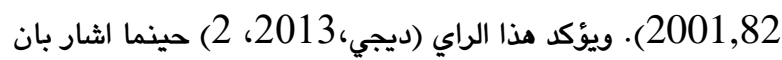
المنظمة يمكن ان تحقق التميز اللوجستي من خلال التركيز على متطلبات الزبائن وحدد هذه المتطلبات ببعدين الاول التسليم من خلال سرعة التسليم الخدمة واحترام اوقات التسليم والتأكد من التسليم والبعد الثاني المطابقة من خلال ضمان بان المنتج المسلم يطابق تماماً

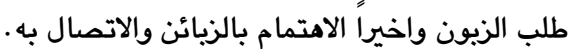
2. تقليل الكلف عبر تصسين العمليات اللوجستية التميز اللوجستي من خلال تقليل الكلف في العمليات التشغيلية لم يعد خيارا في الآونة الاخيرة بل اصبح واقعاً إلزامياً افرزته التنافسية العالمية (Kumar \& Bharathi, 2011, 155)
(Wodalski 381). واستعرض ممارسات النقل الرشيق وصنفها الى ثلاث et al ., 2013, 34) اصناف حسب سهولة تطبيقها: سهل التطبيق وحددها بالممارسات

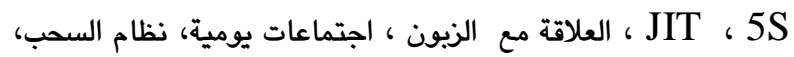
متوسط السهولة وحددما بالممارسات: تقليل حجم الدفعة، تدفق المستمر، وضوح الرؤية، صعبة وحددما بالممارسات: بطاقة كنبان.

\section{- - - - - - نشاط التخزين الرشيق}

يعتبر نشاط التخزين من اهم الانشطة اللوجستية في النظم الصناعية والخدمية وتعتمد على هذا النشاط الحيوي نظم الانتاج وسلاسل التوريد لتأثيرها الكبير على جودة وكلفة المنتجات ومستوى خدمة الزبون

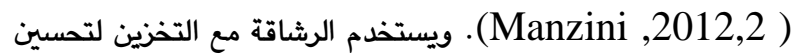
عملياتها والحفاظ على المخزون وتقليل من العمليات التي لا تضيف (Tostar قيمة وتقليل المساحات المخزنية \& Karlsson , 2008,76) وإدارتها بأفضل وسيلة وتحقق الكفاءة فيها مما يقلل من الأنشطة التي لا تضيف قيمة في الاستلام، التخزين، التعبئة والتغليف، الشحن للمواد Gergova,

(Myerson, 2008, 6) (2010, 39) . وتسهم ايضاً بزيادة الاستجابة لطلب الزبائن وتخفيض التكلفة الإجمالية من خلال تبسيط عمليات التوزيع ( ) 2011).وتستخدم المخانن مجموعة من الممارسات والتقنيات الرشيقة التي تسهم في تحسين عمليات التخزين وتعالج او تحد من الهدر والانشطة والعمليات التي لا تضيف قيمة \&harmapriya \& (Kulatunga, 2011, 513). وهذه الممارسات هي: عمليات قياسية، ضمان الجودة، الادارة مرئية، 5S ، حجم دفعات صغيرة ، (Sobanski, 2009, )

تدفق المواد، تحسين مستمر 181. إدارة المرئية، 5S، التحسين المستمر، العمليات القياسية، ادوات ومعدات قياسية، نظام السحب (Bozer, 2012 ) 5S ) ، تدفق القيمة، بناء فريق العمل ، التحسين المستمر، البحث عن المشكلة

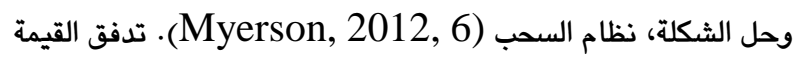
، التحسين المستمر، عمليات وادوات قياسية ، الادارة المرئية ، نظام السحب ، ضمان الجودة ، SWart, 2015, 140) 5S) .

$$
\text { 2.3. التميز اللوجستي: }
$$

يعد اللوجستيك بانها عملية لإدارة استراتيجيات المشتريات والنقل والتخزين داخل المنظمة وخارجها لتوفير احتياجاتها من جهة ولتزويد قنواتها التوزيعية باقل الكلف واكبر الربحية (Law , 2016, 12). ويسبب التطور والتحديات المستمرة التي حصلت في المشهد العالمي للأعمال نتيجة عوامل متعددة مثل قصر دورة حياة المنتجات ودخول المنافسين الجدد والتقلبات في اذواق الزبائن، بالإضافة الى عوامل الاجتماعية الاخلاقية منها والبيئية لتحقيق الاستدامة، جعلت المنظمات 
فالمنظمات تميل المى استخدام نظم المعلومات ويشكل كبير في العمليات التشغيلية ويمكن استغلالها ايضاً كأداة لاتخاذ القرارات الاستراتيجية المتعلقة بالأنشطة اللوجستية ) (مroznik \& Xiong, 2012, 50). ويرى ( Ghiani et al., 2013, 17 )بانه يمكن تحقيق التميز اللوجستي من خلال نظام معلوماتي متطور من خلال نقل المعلومات ويدقة بين المبيعات والمخانن والموردين وجميع الاطراف

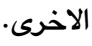

\section{4. الإطار الميداني/ قياس وتحليل النتائج واختبار فرضياتها}

1.4. وصف وتثخيص متغيرات الدراسة:

1. وصف وتثخيص متغيرات انشطة . LSCM حسب

ادراك المبحوثين لكل نشاط:

أ. وصف وتثخيص متغيرات نثاط الشراء الرشيق تشير نتائج الجدول (1) الذي يمثل التوزيعات التكرارية والنسب المئوية والمتوسطات الحسابية والانحرافات المعيارية ونسبة الاستجابة ومعامل الاختلاف للمؤشرات نشاط الشراء الرثيق، الى ان معدل الانسجام العام لإجابات المبحوثين بالاتفاق (أتفق بشدة، أتفق) بلغ (69.9٪) وهذا يدل على أن هناك درجة انسجام عالية في أراء الافراد المبحوثين وتتجه نحو القطب الايجابي بالاعتماد على مقياس (ليكرت) الخماسي وعزز ذلك الوسط الحسابي (3.8) والذي هو اعلى من الوسط الحسابي الفرضي للمقياس (3) وانحراف معياري (0.8) ويلغت قيمة معامل الاختلاف (23٪) ومذا يعني اتفاق المبحوثين ويدرجة واضحة حول هذه المتغيرات وفقا لوجهة نظرهم الشخصية, أما معدل عدم الانسجام (عدم الاتفاق) فقد بلغ (10.5\%) أما القيمة المحايدة فبلغت (19.6٪)

وهي نسبة تشير إلى عدم التأكد أو الثقة وريما عدم المعرفة.

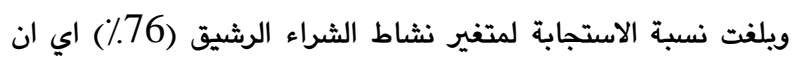
مستوى الادراك ايجابي ويرتقي الى المستوى الرابع (ارتفاع المستوى

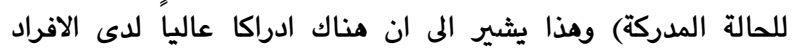

المبحوثين بأهمية تنفيذ هذا النشاط في الشركتين المبحوثتين. ويعد المؤشرات (V3. تجتهد شركتنا باستخدام الشراء الالكتروني لتوفير احتياجاتها من المواد) (V4 . تهتم شركتنا بمعالجة جميع انواع الهدر في نشاط الشراء) من اكثر المؤشرات اسهاما في رفع نسبة الاتفاق لنشاط الشراء الرشيق اذ جاءا بمعدل قدره (78.8 (78) بوسط اهن حسابي (3.9) ويانحراف معياري (0.8) ، ويفسر نتائج المؤشرين بان الشركتين تعتمدان الشراء الالكتوني لتوفير احتياجاتها من المواد وكذلك يبين حرص الشركتين في معالجة جميع انواع الهدر في نشاط
المنخفضة ليس بالأمر السهل وهذا ما اشره البحوث والدراسات على ان اهم المعوقات التي تواجه مدراء اللوجستيك هي زيادة التكلفة في ومن الانشطة اللوجستية)(Genpact,2015, 2). منطلق اهمية وصعوية تحقيق الكلفة المنخفضة في الانشطة اللوجستية يرى العديد من الكتاب بان هدف اي نظام لوجستي هو تدقيق الربحية من خلال تخفيض التكاليف وخلال فترات زمنية قصيرة واعطاء دعم مطلوب للزبائن يكون احد المتطلبات لتحقيق التميز اللوجستي ويهذا ستكون المنظمة بحاجة الى تحسين من ادائها الداخلي والخارجي، الداخلي يمكن تحقيقه من خلال تقليل وقت الدورة الانتاجية، اما الخارجي فيمكن تدقيقه من خلال دقة التوقيت والتسليم وانخفاض الاسعار (Pettersson, 2015, 18). 3. العلاقة مع الموردين نتائج الدراسة (Mentzer, 2001, 83) اثارت بان العلاقة مع الموردين تعتبر احدى الابعاد الرئيسة لجودة الخدمة اللوجستية وتؤثر بشكل كبير على جودة الخدمة اللوجستية المقدمة ويمكن ان تساهم بشكل كبي في خفض التكاليف وتحقق التميز اللوجستي. التعاون ويناء العلاقات الجيدة ذات الامد الطويل بين المنظمة والموردين مهمة جداً وتعتبر من المبادئ الاساسية لتحقيق المنافع المتبادلة وتحقيق التميز اللوجستي (Groznik \& Xiong, 2012, 49).

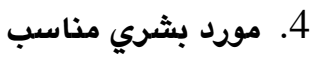
تستطيع الشركات من تحقيق التميز اللوجستي من خلال وجود مورد

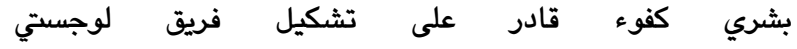

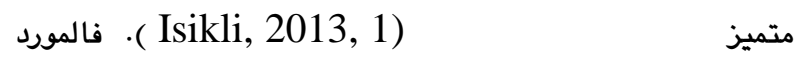
البشري المناسب يلعب دورا ماما ومحورياً في تحقيق التميز اللوجستي والمدراء يدركون أهميته لممارسة وتنفيذ الانشطة اللوجستية لذا يقومون اولا بتقييم الموظفين وتدريبهم ويعدها اشراكهم في تنفيذ Groznik \& Xiong, )

الانشطة اللوجستية 2012, 49 (2012). وتشير نتائج الدراسات في مجال إدارة اللوجستيات وسلسلة التوريد إلى أن نقص المورد البشري في مجال اللوجستيات أصبح مسألة لم يعد من الممكن تجاهلها، وأثار معهد آسيا والمحيط الهادئ للوجستيات في سنغافورة أن نقص الخبرة في مجال إدارة اللوجستيات يشكل عقبة أمام تطوير ادارة اللوجستيات وسلاسل

التوريد (Okeduo, 2012,1)

5. نظام معلوماتي متقدم

تمتاز نظم المعلومات بأهمية كبيرة بالنسبة للمنظمات لتحقيق التميز اللوجستي، وتستخدم اغلب المنظمات نظام معلومات متطور لإدارة الانشطة اللوجستية في مذا المجال ويقدم نظام المعلومات المتطور مجال كبير للمنظمة للتحسين من انشطتها ولتحقيق التميز اللوجستي، 
(33.3) بين المؤشرات النشاط ، وهذا يدل على ان الشركتين ليس من سياستها التعامل مع عدد قليل من الموردين.
وعكس المؤشر (V8 . تتعامل شركتنا مع عدد قليل من الموردين)،

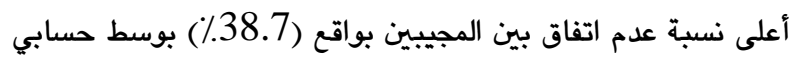

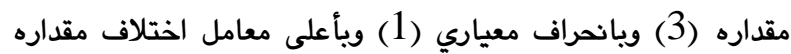
الجدول 1: التوزيعات التكرارية والأوساط الحسابية والانحرافات المعيارية ونسبة الاستجابة ومعامل الاختلاف لمتغير نشاط الشراء الرشيق في الشركتين المبحوثتين

\begin{tabular}{|c|c|c|c|c|c|c|c|c|c|c|c|c|c|c|c|}
\hline \multirow{3}{*}{ 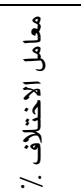 } & \multirow{3}{*}{ 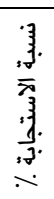 } & \multirow{3}{*}{$\begin{array}{l}\overline{3} \\
\bar{g} \\
\xi \\
y_{3}\end{array}$} & \multirow{3}{*}{ 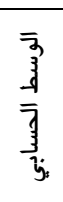 } & \multicolumn{10}{|c|}{ مقياس الاستجابة } & \multirow{3}{*}{$\frac{3}{3}$} & \multirow{3}{*}{ 高 } \\
\hline & & & & \multicolumn{2}{|c|}{ لا اتفق شدة } & \multicolumn{2}{|c|}{ لا لاتق } & \multicolumn{2}{|c|}{ محايد } & \multicolumn{2}{|c|}{ أتفق } & \multicolumn{2}{|c|}{ أتفق بشدة } & & \\
\hline & & & & $\%$ & عدد & $\%$ & عدد & $\%$ & عدد & $\%$ & عدد & $\%$ & عدد & & \\
\hline 20 & 80 & 0.8 & 4 & - & - & 3.8 & 3 & 20 & 16 & 47.5 & 38 & 28.8 & 23 & V1 & \\
\hline 20 & 80 & 0.8 & 4 & - & - & 7.5 & 6 & 15 & 12 & 47.5 & 38 & 30 & 24 & $\mathrm{~V} 2$ & $\frac{3}{4}$ \\
\hline 20.5 & 78 & 0.8 & 3.9 & - & - & 6.2 & 5 & 15 & 12 & 55 & 44 & 23.8 & 19 & V3 & $\overline{3}$ \\
\hline 20.5 & 78 & 0.8 & 3.9 & - & - & 6.2 & 5 & 15 & 12 & 53.8 & 43 & 25 & 20 & V4 & 4 \\
\hline 23 & 78 & 0.9 & 3.9 & - & - & 7.5 & 6 & 21.2 & 17 & 41.2 & 33 & 30 & 24 & V5 & $\tau$ \\
\hline 23.6 & 76 & 0.9 & 3.8 & 2.5 & 2 & 6.2 & 5 & 21.2 & 17 & 45 & 36 & 25 & 20 & V6 & $\ddot{z}$ \\
\hline 20.5 & 78 & 0.8 & 3.9 & - & - & 5 & 4 & 22.5 & 18 & 45.0 & 36 & 27.5 & 22 & V7 & 1 \\
\hline 33.3 & 60 & 1 & 3 & 2.5 & 2 & 36.2 & 29 & 26.2 & 21 & 26.2 & 21 & 8.8 & 7 & V8 & $\overrightarrow{.}$ \\
\hline 23 & 76 & 0.8 & 3.8 & 0.6 & & 9.9 & & 19.6 & & 45.2 & & 24.7 & & العام & $z^{z}$ \\
\hline
\end{tabular}

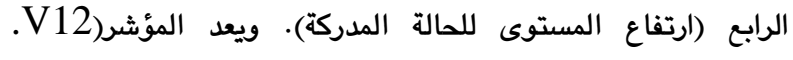
تستخدم شركتنا وسائل نقل مناسبة تناسب طبيعة اسواقها) من اكثر المؤشرات اسهاما في رفع نسبة الاتفاق لنشاط الشراء الرشيق اذ جاءا بمعدل قدره (87.6\%) بوسط حسابي (4.1) ويانحراف معياري (0.5)، ويشير ذلك ان الشركتين لديها وسائل النقل الضرورية المناسبة لنقل منتجاتها الى اسواقها سواء داخل الاقليم او خارجها. ولم تسهم كثيراً مؤثرات المتغير في زيادة نسبة عدم اتفاق بين المجيبين الا انه يمكن ملاحظة بان مؤثرات (V16, v13) كانوا مؤثرين بتساوي ولكن بنسبة قليلة بلفت (5\%).

\section{ب. وصف وتثخيص متغيرات نثاط النقل الرشيق} تعرض نتائج الجدول (2) الذي يمثل التوزيعات التكرارية والنسب المئوية والمتوسطات الحسابية والانحرافات المعيارية ونسبة الاستجابة ومعامل الاختلاف للمؤشرات الخاصة بمتغير نشاط النقل الرشيق، الى

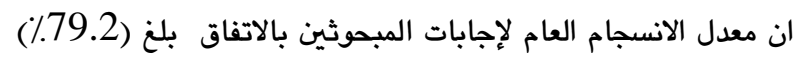
وعزز ذلك الوسط الحسابي الذي بلغ مقداره (4) وانحراف المعياري

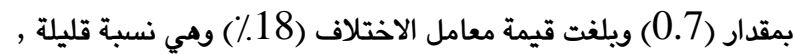
أما معدل عدم الانسجام (عدم الاتفاق) فقد بلغ (3.2٪) ويلغت القيمة المحايدة (17.6٪). ويلغت نسبة الاستجابة لمتغير نشاط المورد الرثيق (79٪) اي ان مستوى الادراك ايجابي ويرتقي الى المستوى

الجدول 2: التوزيعات التكرارية والأوساط الحسابية والانحرافات المعيارية ونسبة الاستجابة ومعامل الاختلاف لمتغير نشاط النقل الرشيق في الشركتين المبحوثتين

\begin{tabular}{|c|c|c|c|c|c|c|c|c|c|c|c|c|c|c|c|}
\hline \multirow{3}{*}{ 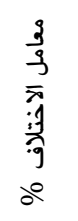 } & \multirow{3}{*}{ 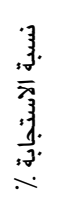 } & \multirow{3}{*}{$\begin{array}{l}\overline{3} \\
\bar{g} \\
3 \\
3 \\
\overline{3}\end{array}$} & \multirow{3}{*}{ 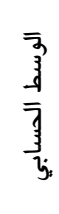 } & \multicolumn{10}{|c|}{ مقياس الاستجابة } & \multirow{3}{*}{$\frac{\hat{3}}{\hat{3}}$} & \multirow{3}{*}{$\begin{array}{l}\overline{1} \\
\bar{n} \\
\overline{3}\end{array}$} \\
\hline & & & & \multicolumn{2}{|c|}{ لا أتفق بشدة } & \multicolumn{2}{|c|}{ لا اتفق } & \multicolumn{2}{|c|}{ محايد } & \multicolumn{2}{|c|}{ أتفق } & \multicolumn{2}{|c|}{ أتفق بشدة } & & \\
\hline & & & & $\%$ & عدد & $\%$ & عدد & $\%$ & عدد & $\%$ & عدد & $\%$ & عدد & & \\
\hline 15 & 80 & 0.6 & 4 & - & - & - & - & 17.5 & 14 & 57.5 & 46 & 25 & 20 & V9 & \\
\hline 20 & 80 & 0.8 & 4 & 1.2 & 1 & 3.8 & 3 & 12.5 & 10 & 55 & 44 & 27.5 & 22 & V10 & id \\
\hline 17.5 & 80 & 0.7 & 4 & - & - & 3.8 & 3 & 18.8 & 15 & 50 & 40 & 27.5 & 22 & V11 & \\
\hline 12.2 & 82 & 0.5 & 4.1 & - & - & - & - & 12.5 & 10 & 63.8 & 51 & 23.8 & 19 & V12 & \\
\hline 20 & 80 & 0.8 & 4 & - & - & 5 & 4 & 16.2 & 13 & 51.2 & 41 & 27.5 & 22 & V13 & 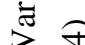 \\
\hline 18 & 78 & 0.7 & 3.9 & - & - & 3.8 & 3 & 18.8 & 15 & 53.8 & 43 & 23.8 & 19 & V14 & 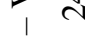 \\
\hline 21 & 76 & 0.8 & 3.8 & 1.2 & 1 & 2.5 & 2 & 27.5 & 22 & 47.5 & 38 & 21.2 & 17 & V15 & I \\
\hline 18 & 78 & 0.7 & 3.9 & - & - & 5 & 4 & 17.5 & 14 & 52.5 & 42 & 25 & 20 & V16 & $\frac{\pi}{\pi}$ \\
\hline 18 & 79 & 0.7 & 4 & 0.3 & & 2.9 & & 17.6 & & 54 & & 25.2 & & المعدل العام & \\
\hline
\end{tabular}


ويعد المؤشر(V18. تهدف ادارة المخانن في شركتنا التخلص من

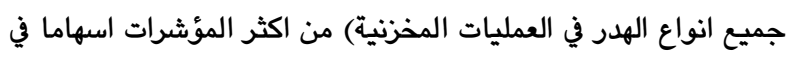
رفع نسبة الاتفاق لنشاط التخزين الرشيق اذ جاءا بمعدل قدره

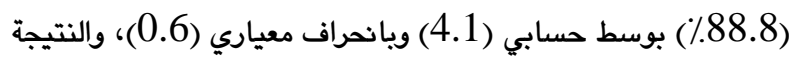
توضح حقيقة عمل الشركتين عند ادارة عملياتها المخزنية من نقل ومناولة واستلام وصرف والجرد وغيرها من العمليات بحيث يتم القضاء على جميع انواع الهدر فيها. وساهم المؤشر (V24. يسهم نظام المعلومات المخزنية في الشركة على الهي تجنب حدوث اخطاء مخزنية)، أعلى نسبة عدم اتفاق بين المجيبين

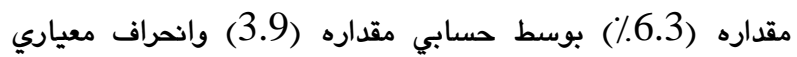

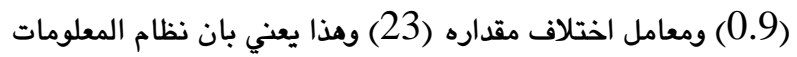
المخزنية حتى بوجوده يحدث هناك اخطاء وهدر في الانشطة المخزنية وهذا ما اشره الباحثين ايضاً عندما سجل بعض حالات التلف والخزين الزائد عند مخازن الشركتين وحسب معلومات أمين المخزن.

\section{ج. وصف وتشخيص متفيرات نشاط التخزين الرشيق} تشير نتائج الجدول (3) الذي يمثل التوزيعات التكرارية والنسب المئوية والمتوسطات الحسابية والانحرافات المعيارية ونسبة الاستجابة ومعامل الاختلاف لمؤشرات نشاط التخزين الرشيق، الى ان معدل الانسجام العام

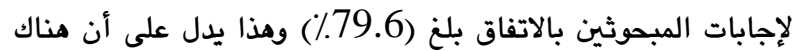
درجة انسجام عالية في أراء الافراد المبحوثين ويوسط حسابي مقداره

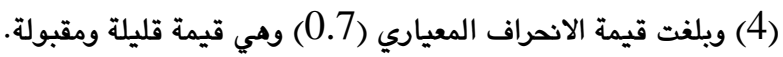

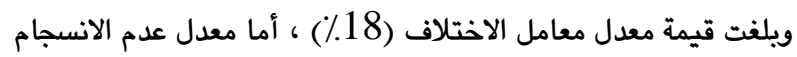
(عدم الاتفاق) فقد بلغ (2.9٪) وهي نسبة قليلة جداً، أما القيمة الانسام المحايدة فبلغت (17.5٪). ويلغت نسبة الاستجابة لمتغير نشاط

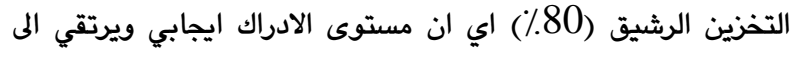

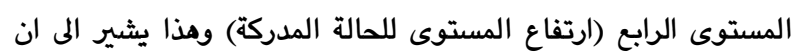

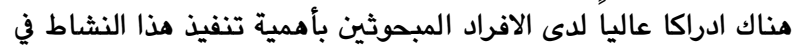

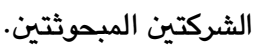
الجدول 3: التوزيعات التكرارية والأوساط الحسابية والانحرافات المعيارية ونسبة الاستجابة ومعامل الاختلاف لمتغير نشاط التخزين الرشيق في

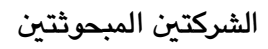

\begin{tabular}{|c|c|c|c|c|c|c|c|c|c|c|c|c|c|c|c|}
\hline \multirow{3}{*}{ 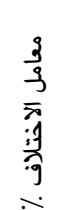 } & \multirow{3}{*}{ 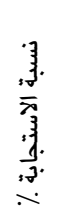 } & \multirow{3}{*}{$\begin{array}{l}\overline{3} \\
\overline{9} \\
3 \\
3 . \\
3\end{array}$} & \multirow{3}{*}{$\begin{array}{l}\overline{3} \\
\frac{3}{d} \\
\overline{\bar{h}} \\
\frac{3}{3}\end{array}$} & \multicolumn{10}{|c|}{ مقياس الاستجابة } & \multirow{3}{*}{$\frac{\hat{3}}{\overline{3}}$} & \multirow[b]{3}{*}{3} \\
\hline & & & & \multicolumn{2}{|c|}{ لا أتفق بشدة } & \multicolumn{2}{|c|}{ لا أتفق } & \multicolumn{2}{|c|}{ محايد } & \multicolumn{2}{|c|}{ أتفق } & \multicolumn{2}{|c|}{ أتفق بشدة } & & \\
\hline & & & & $\%$ & عدد & $\%$ & عدد & $\%$ & عدد & $\%$ & عدد & $\%$ & عدد & & \\
\hline 14.6 & 82 & 0.6 & 4.1 & - & - & 1.2 & 1 & 11.2 & 9 & 55 & 44 & 32.5 & 26 & V17 & 司 \\
\hline 14.6 & 82 & 0.6 & 4.1 & - & - & 1.2 & 1 & 10 & 8 & 60 & 48 & 28.8 & 23 & V18 & 3 \\
\hline 20.5 & 78 & 0.8 & 3.9 & 1.5 & 1 & 2.5 & 2 & 17.5 & 14 & 53.8 & 43 & 25 & 20 & V19 & \\
\hline 17.5 & 80 & 0.7 & 4 & - & - & 2.5 & 2 & 15 & 12 & 58.8 & 47 & 23.8 & 19 & V20 & \\
\hline 20 & 80 & 0.8 & 4 & - & - & 5 & 4 & 18.8 & 15 & 47.5 & 38 & 28.8 & 23 & V21 & $\sum^{ \pm / \pi}$ \\
\hline 20 & 80 & 0.8 & 4 & 1.5 & 1 & 2.5 & 2 & 21.2 & 17 & 43.8 & 35 & 31.2 & 25 & V22 & \\
\hline 17.5 & 80 & 0.7 & 4 & - & - & - & - & 25 & 20 & 43.8 & 35 & 31.2 & 25 & V23 & c \\
\hline 23 & 78 & 0.9 & 3.9 & 2.5 & 2 & 3.8 & 3 & 21.2 & 17 & 42.5 & 34 & 30 & 24 & V24 & \\
\hline 18 & 80 & 0.7 & 4 & 0.6 & & 2.3 & & 17.5 & & 50.7 & & 28.9 & & المعدل العام & \\
\hline
\end{tabular}

الشركتين المبحوثتين. والمؤشر(V36. تدرك شركتنا بان تحقيق التميز اللوجستي لا يتحقق بدون وجود تعاون وثيق بينها وبين

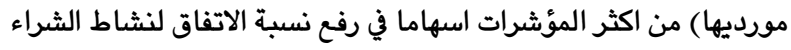
الرشيق اذ جاءا بمعدل قدره (85٪) بوسط حسابي (4) ويانحراف معياري (0.6)، وتبين هذه النتيجة حقيقة بان التميز اللوجستي

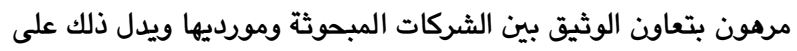

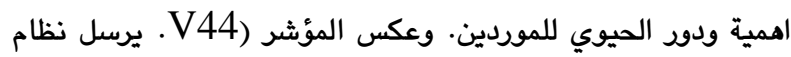

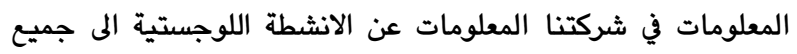

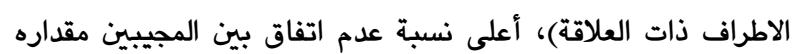
(11.2\%) وهي نسبة قليلة جداً بوسط حسابي مقداره (3.6)

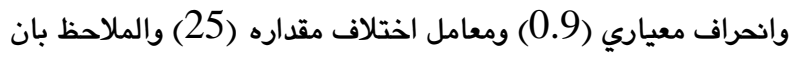
مضمون هذا المؤشر يتوافق مع المؤشر التي حصل على اعلى نسبة

\section{ت. وصف وتشخيص متغيرات التميز اللوجستي} تشير نتائج الجدول (4) الذي يمثل التوزيعات التكرارية والنسب المئوية والمتوسطات الحسابية والانحرافات المعيارية ونسبة الاستجابة ومعامل الاختلاف للمؤشرات الخاصة بمتغير التميز اللوجستي، الى ان معدل الانسجام العام لإجابات المبحوثين بالاتفاق (أتفق بشدة، أتفق) بلغ (73.9٪) وعزز ذلك الوسط الحسابي (3.9) , بينما بلغ قيمة

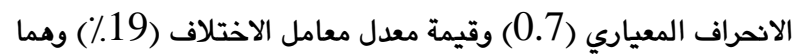
قيمتان قليلتان, أما معدل عدم الانسجام (عدم الاتفاق) فقد بلغ (4.1\%) وهي نسبة قليلة جدا، أما القيمة المحايدة فبلفت (21.9٪) ويلغت نسبة الاستجابة (79٪) اي ان مستوى الادراك ايجابي ويرتقي الى المستوى الرابع (ارتفاع المستوى للحالة المدركة) وهذا يشيى الى ان

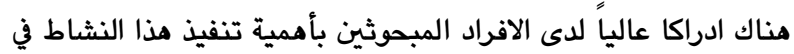


استجابة ولكن بما ان النتيجة قليلة فقد يكون هناك عدم تصور واضح لدى المجيبين حول هذا المؤشر او نظام المعلوماتي في الشركات المبحوثة غير كفوء.

الجدول 4: التوزيعات التكرارية والأوساط الحسابية والانحرافات المعيارية ونسبة الاستجابة ومعامل الاختلاف لمتغير التميز اللوجستي في الشركتين المبحوثتين

\begin{tabular}{|c|c|c|c|c|c|c|c|c|c|c|c|c|c|c|c|}
\hline \multirow{3}{*}{ 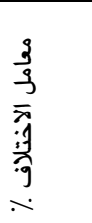 } & \multirow{3}{*}{ 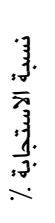 } & \multirow{3}{*}{$\begin{array}{l}\overline{3} \\
\bar{y} \\
\xi \\
\overline{3} .\end{array}$} & \multirow{3}{*}{$\begin{array}{l}\overline{\bar{j}} \\
\bar{j} \\
\bar{j} \\
\overline{3}\end{array}$} & \multicolumn{10}{|c|}{ مقياس الاستجابة } & \multirow{3}{*}{$\frac{?}{3}$} & \multirow{3}{*}{$\frac{\overline{3}}{\overline{3}}$} \\
\hline & & & & \multicolumn{2}{|c|}{ لا اتفق بشدة } & \multicolumn{2}{|c|}{ لا لا اتفق } & \multicolumn{2}{|c|}{ محايد } & \multicolumn{2}{|c|}{ أتفق } & \multicolumn{2}{|c|}{ بشدة أتفق } & & \\
\hline & & & & $\%$ & عدد & $\%$ & عدد & $\%$ & عدد & $\%$ & عدد & $\%$ & عدد & & \\
\hline 17.5 & 80 & 0.7 & 4 & - & - & 2.5 & 2 & 20 & 16 & 43.8 & 35 & 33.8 & 27 & V25 & \\
\hline 15.7 & 76 & 0.6 & 3.8 & - & - & 1.2 & 1 & 25 & 20 & 58.8 & 47 & 15 & 12 & V26 & \\
\hline 18 & 78 & 0.7 & 3.9 & - & - & 2.5 & 2 & 20 & 16 & 57.5 & 46 & 20 & 16 & V27 & \\
\hline 18 & 78 & 0.7 & 3.9 & - & - & 1.2 & 1 & 26.2 & 21 & 45 & 36 & 26.2 & 21 & V28 & \\
\hline 19.5 & 82 & 0.8 & 4.1 & - & - & 1.2 & 1 & 20 & 16 & 43.8 & 35 & 35 & 28 & V29 & \\
\hline 18 & 78 & 0.7 & 3.9 & - & - & 3.8 & 3 & 21.2 & 17 & 57.5 & 46 & 17.5 & 14 & V30 & \\
\hline 15.3 & 78 & 0.6 & 3.9 & - & - & 1.2 & 1 & 20 & 16 & 61.2 & 49 & 17.5 & 14 & V31 & .2 \\
\hline 20.5 & 78 & 0.8 & 3.9 & 1.2 & 1 & 3.8 & 3 & 23.8 & 19 & 47.5 & 38 & 23.8 & 19 & V32 & $z^{\prime}$ \\
\hline 18 & 78 & 0.7 & 3.9 & - & - & 3.8 & 3 & 16.2 & 13 & 61.2 & 49 & 18.8 & 15 & V33 & $\overline{3}$ \\
\hline 20 & 80 & 0.8 & 4 & - & - & 3.8 & 3 & 21.2 & 17 & 43.8 & 35 & 31.2 & 25 & V34 & $\stackrel{3}{\approx}$ \\
\hline 20.5 & 78 & 0.8 & 3.9 & 0.2 & 1 & 6.2 & 5 & 10 & 8 & 61.2 & 49 & 21.2 & 17 & V35 & \\
\hline 15 & 80 & 0.6 & 4 & - & - & 1.2 & 1 & 13.8 & 11 & 62.5 & 50 & 22.5 & 18 & V36 & ت் \\
\hline 15.3 & 78 & 0.6 & 3.9 & - & - & 2.5 & 2 & 17.7 & 14 & 60 & 48 & 20 & 16 & V37 & I \\
\hline 21 & 76 & 0.8 & 3.8 & - & - & 7.5 & 6 & 22.5 & 18 & 46.2 & 37 & 23.8 & 19 & V38 & g \\
\hline 21 & 76 & 0.8 & 3.8 & - & - & 5 & 4 & 30 & 24 & 45 & 36 & 20 & 16 & V39 & ह் \\
\hline 18 & 78 & 0.7 & 3.9 & - & - & 2.5 & 2 & 23.8 & 19 & 51.2 & 41 & 22.5 & 18 & V40 & $z$ \\
\hline 20.5 & 78 & 0.8 & 3.9 & - & - & 3.8 & 3 & 26.2 & 21 & 42.5 & 34 & 27.5 & 22 & V41 & \\
\hline 20.5 & 78 & 0.8 & 3.9 & & - & 6.2 & 5 & 23.8 & 19 & 42.5 & 34 & 27.5 & 22 & V42 & \\
\hline 23.6 & 76 & 0.9 & 3.8 & 1.2 & 1 & 8.8 & 7 & 26.2 & 21 & 35 & 28 & 28.8 & 23 & V43 & \\
\hline 25 & 72 & 0.9 & 3.6 & 1.2 & 1 & 10 & 8 & 30 & 24 & 38.8 & 31 & 20 & 16 & V44 & \\
\hline 19 & 79 & 0.7 & 3.9 & 0.2 & & 3.9 & & 21.9 & & 50.3 & & 23.6 & & المعدل العام & \\
\hline
\end{tabular}

منفردة والتميز اللوجستي عند مستوى معنوية(0.01)، تسلسلت قيمة المؤشر من التخزين الرشيق (*0.763) تلاه الشراء الرشيق

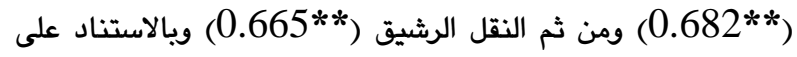
نتائج السابقة سيتم قبول فرضية الثانية. وتدل هذه النتائج على وجود علاقة الارتباط بين انشطة LSCM مجتمعة ومنفردة والتميز اللوجستي، ويزداد علاقة الارتباط عند تطبيق

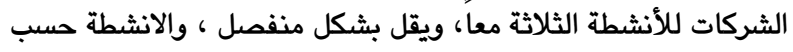
قوة علاقة الارتباط مع التميز اللوجستي تبدأ من التخزين الرشيق ثم الشراء الرشيق ثم النقل الرشيق.
2.4. اختبار فرضية الارتباط:

يشير مضمون الفرضيات الاولى والثانية الأولى إلى وجود علاقة ارتباط

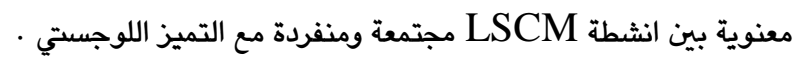
وتشير نتائج الجدول (5) والذي يوضح علاقة الارتباط بين متغيرات الدراسة بوجود علاقة ارتباط معنوية عالية بين انشطة LSCM مجتمعة والتميز اللوجستي بلغ قيمة معامل الارتباط الكلي (0.814)عند مستوى معنوية (0.01)، ويذلك سيتم قبول فرضية الاولى، بالإضافة الى وجود علاقة ارتباط معنوية بين انشطة LSCM الجدول 5: قيم معامل الارتباط البسيط بين انشطة LSCM مجتمعة ومنفردة والتميز اللوجستي

\begin{tabular}{|c|c|c|c|}
\hline لـتنيجة الاختبار & $\begin{array}{l}\text { قيمة مؤشر الارتباط } \\
\text { Correlation coefficient }\end{array}$ & انشطة LSCM & لفرضيات \\
\hline قبول الفرضية & $0.814 * *$ & 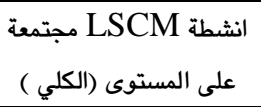 & | الاولى \\
\hline
\end{tabular}




\begin{tabular}{|c|c|c|c|c|}
\hline & قبول الفرضية & $0.682 * *$ & الشراء الرشيق & \multirow[t]{3}{*}{ لثانية } \\
\hline & قبول الفرضية & $0.665 * *$ & النقل الرشيق & \\
\hline & قبول الفرضية & $0.763 * *$ & التخزين الرشيق & \\
\hline $\mathrm{N}=80$ & \multicolumn{3}{|c|}{$* * \mathrm{P}-$ Value $\leq 0.01$} & \\
\hline
\end{tabular}

مستجيبة. وهو ما أشرته نتائج التحليل لقيم معاملات (B) وقيمة Fل

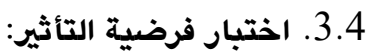

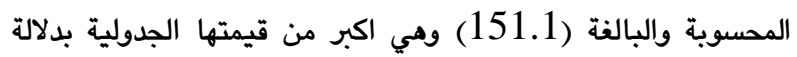

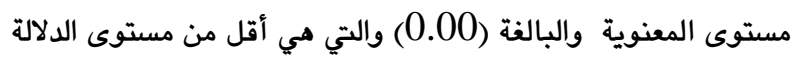

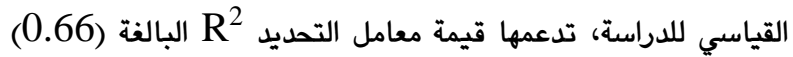

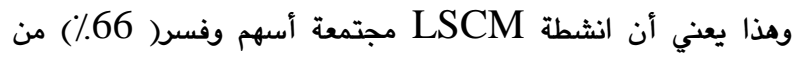

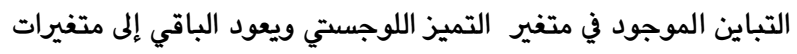

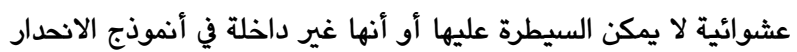
أصلاً.

يشير مضمون الفرضيات الثالثة والرابعة إلى وجود تأثير معنوي بين انشطة LSCM مجتمعة ومنفردة في التميز اللوجستي. يشير مضمون الفرضية الثالثة إلى وجود تأثير معنوي لأنشطة LSCM مجتمعة في التميز اللوجستي ومن خلال نتائج الجدول (6) الخاص بنتائج تحليل

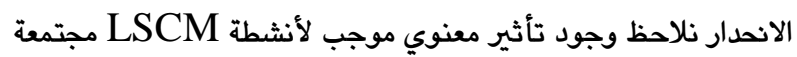
بوصفها متغيرات تفسيرية في متغير التميز اللوجستي بوصفها متغيرات

الجدول 6: تحليل علاقة تأثير لأنشطة LSCM مجتمعة في التميز اللوجستي

\begin{tabular}{|c|c|c|c|c|c|c|c|c|}
\hline النتيجة & Sig & $\mathrm{t}$ & $\mathrm{F}$ & $\mathrm{R}^{2}$ & Beta & \multicolumn{2}{|c|}{ انشطة LSCM مجتمعة } & الفرضية \\
\hline \multirow[t]{2}{*}{ قبول الفرضية } & \multirow[t]{2}{*}{0.00} & \multirow{2}{*}{$\begin{array}{l}1.077 \\
12.29\end{array}$} & \multirow[t]{2}{*}{151.1} & \multirow[t]{2}{*}{0.66} & \multirow[t]{2}{*}{0.814} & B1 & $\mathrm{B}_{0}$ & \multirow[t]{2}{*}{ الثالثة } \\
\hline & & & & & & 0.914 & 0.319 & \\
\hline
\end{tabular}

المتغير المعتمد (المستجيب) التميز اللوجستي N=80

ويشير مضمون الفرضية الرابعة إلى وجود تأثير معنوي لأنشطة معاملات (B) و) (R2) . وكانت نشاط التخزين الرشيق اكثرهم تأثيرا

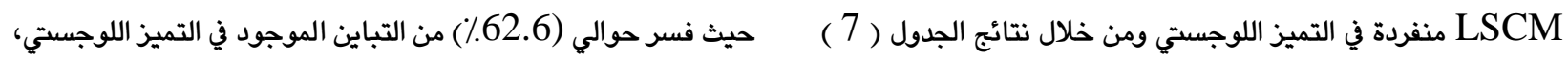

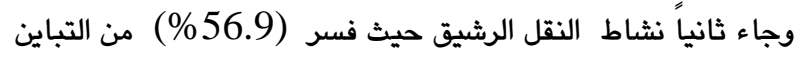
نلاحظ وجود تأثير معنوي موجب لكل نشاط من انشطة LSCM في التميز اللوجستي ، تلاهم نشاط الشراء الرشيق بنسبة تفسير في التميز اللوجستي بدلالة قيمة t المحسوية للأنشطة التي هي اكبر من

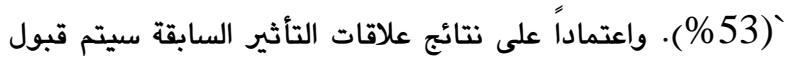

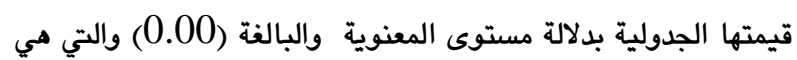
أقل من مستوى الدلالة القياسي للدراسة ، ودعمت هذه النتيجة قيمة فرضية الرابعة . الجدول 7: تحليل علاقة تأثير لأنشطة LSCM منفردة في التميز اللوجستي

\begin{tabular}{|c|c|c|c|c|c|c|c|c|}
\hline النتيجة & Sig. & Beta & $\mathrm{F}$ & $\mathrm{R}^{2}$ & $\begin{array}{l}\text { B0 } \\
\text { B1 }\end{array}$ & $\mathrm{t}$ & 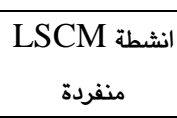 & الفرضية \\
\hline \multirow[t]{3}{*}{ قبول الفرضية } & $0.00 \square$ & 0.633 & 51.418 & 0.530 & $\begin{array}{l}1.930 \\
0.536 \square\end{array}$ & $\begin{array}{l}6.667 \\
7.171\end{array}$ & الشراء الرشيق & \multirow{3}{*}{ الرابعة } \\
\hline & 0.00 & 0.665 & 60.931 & 0.569 & $\begin{array}{l}1.576 \\
0.601 \\
\end{array}$ & $\begin{array}{l}5.068 \\
7.806 \\
\end{array}$ & النقل الرشيق & \\
\hline & $0.00 \square$ & 0.742 & 94.462 & 0.626 & $\begin{array}{l}1.189 \\
0.690\end{array}$ & $\begin{array}{l}4.103 \\
9.719\end{array}$ & التخزين الرشيق & \\
\hline$=80$ & .01 & ,77) & التميز اللو & مد (I) & $\begin{array}{ll}1 \\
1\end{array}$ & & & \\
\hline
\end{tabular}

المبادئ والممارسات والتقنيات الرشيقة التي يجب ان تستخدم مع كل نشاط. 2. اظظهرت نتائج تحليل الوصــف والتشـــيص بان اجابات الافراد

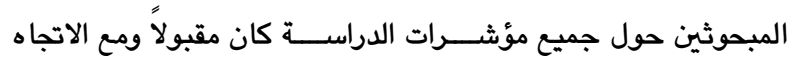

5. الاستنتاجات والمقترحات

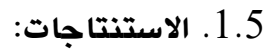

1. على الرغم من اهتمام الشركتين المبحوثتين بمفهوم أنشطة إدارة

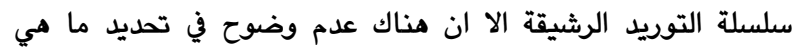


ديجي ، وهبية ، 2013 ، دود استراتيجية التميز في تصسين اداء المؤسسة الاقتصادية ، رسالة ماجستير غير منشورة ، جامعة محمد خيضر- بسكرة ، الجزائر.

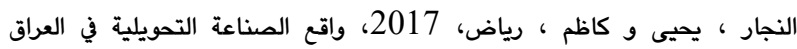

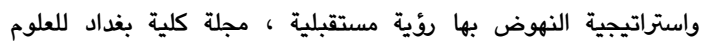
الاقتصادية الجامعة ، العدد (50).

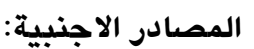

Afonso, H., Cabrita, M., 2015, Developing a lean supply chain performance framework in a SME: A perspective based on the balanced scorecard. "Published by Elsevier Procedia Engineering", 131 ( 1 ).

Agus, A., \& Hajinoor, S., 2012, "Lean production supply chain management as driver towards enhancing product quality and business performance", International Journal of Quality \& Reliability Management, Vol. 29, No. 1.

Al-Aomar, R. \& Weriakat, D. (2012), A Framework for a Green and Lean Supply Chain: A Construction Project Application, Proceedings of the 2012 International Conference on Industrial Engineering and Operations Management Istanbul, Turkey, July 3-6.

Al-Tit A., 2016, The impact of lean supply chain Management on Productivity of study Manufacturing firm in Al-Qassim region, "Poliash Journal of Management Studies", 14(1).

Arriaga, J., Cárdenas, C., Rivera, J., and Sada, J., 2013, A Lean Route to Increase Transportation Agility and Food Freshness, Proceedings of the 2013 Industrial and Systems Engineering Research Conference A.Krishnamurthy and W.K.V. Chan, Eds.

ARC, 2014, Operational Excellence in Inbound Logistics: A Strategy for Profitable Growth in Retail. WWW.images.fedex.com

Behrouzi, F., Wong, K., 2011, An investigation and identification of lean supply chain performance measures in the automotive SMEs, Scientific Research and Essays, 6(24).

Belekoukias, L., Garza-Reyes, A., and Kumar, V.,2017, The impact of lean methods and tools on the operational performance of manufacturing organizations, International Journal of Production, 52(18).

Bozer, A., 2012, Developing and Adapting Lean Tools, Techniques to Build New Curriculum, Training Program in Warehousing and Logistics, Department of Industrial and Operations Engineering, University of Michigan Ann Arbor. yabozer@umich.edu .

Campbell T., Stanley C., 1963, Experimental and quasiexperimental designs for research, Boston, Houghton Mifflin.

Costantino , F., Gravio, G ., and Nonino , F., 2015, Insights from action research: implementing an innovative lean procurement framework for global sourcing, international business management journal, 9(4).

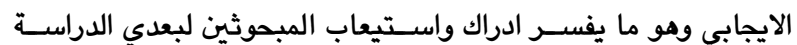
أنشطة ادارة سلسلة التوريد الرشيق والتميز اللوجستي. 3. اتسمت علاقات الارتباط بين ابعاد ومتغيرات الدراسة بالمعنوية واثبتت النتائج صــــة الفرضـــية المتعلقة بالارتباط، وتفاوت قيمة معامل الارتباط على المسـتوى الكلي والفردي (على المسـتوى الكلي

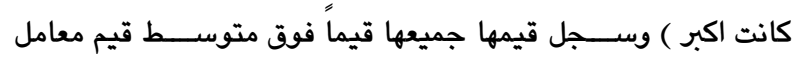
الارتباط وبالاتجاه الايجابي، ومذا مؤثـــر دال على قوة العلاقة التي تربط ابعاد ومتغيرات الدراسة ومنطلق نحو تدعيم فكرة الدراسة. 4. تأكد وجود تأثير معنوي لأنشطة ادارة سلسلة التوريد الرشيقة مجتمعة ومنفردة في متطلبات التميز اللوجســـتي، تأثيرما اكبر عندما تكون مجتمعة واثبتت النتائج صحة الفرضية المتعلقة بالتأثير .

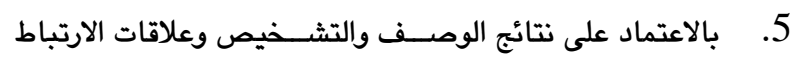
والتأثير ذستنتج بان أذشطة إدارة سلسلة التوريد الرشيق تسهم في تحقيق التميز اللوجستي. 2.5 - 2. - 2. المقترحات:

1. الامتمام العالي بمفهوم ادارة سلسلة التوريد الرشيقة وأنشطته وابرازه كتوجه اسـتراتيجي متوافق مع التغيرات الحاصـلة في سـلاسـل التوريد ومتوافق مع مصالح العليا لجميع الاطراف المشاركين، ودعمه وتحقيقه التميز في الانشطة اللوجستية.

2. تحديد ويدقة ما مي المبادئ والممارســات والتقنيات الرثــيقة اللازمة مع كل نشاط من أنشطة إدارة سلسلة التوريد.

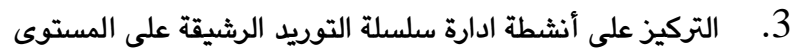
الكلي اي عندمـا تكون مجتمعــة لزيـادة القوة الترابطيـة والتـاثيريـة

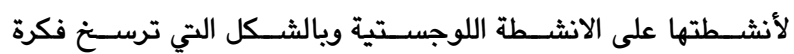
التخطيط والتنسيق المشترك والعمل وتحرك الكفوء للأنشطة.

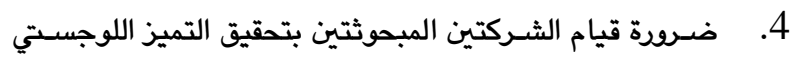
من منطلق امتلاك الشـــركتين المبحوثتين لإمكانيات متفوقة والخبرة اللازمة، وسلاسل توريد متصفة بالرشاقة.

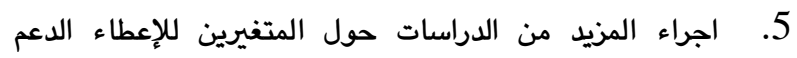
والمصداقية للدراسة الحالية بتطبيقها على نفس القطاع او قطاعات مشابهه اخرى، وخاصة بعد التأكد من قلة الدراسات التي درست مفهوم

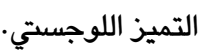

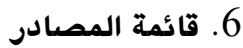

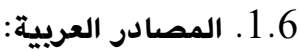

إدريس، ثابت عبد الرحمن، 2006، كفاءة وجودة الخدمات اللوجستية: مفاهيم أساسية وطرق القياس والتقييم ، الدار الجامعية للطباعة والنشر،

$$
\text { الإسكندرية، مصر. }
$$

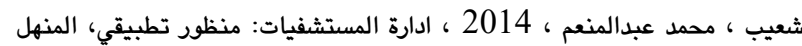
اللنشر والتوزيع ، الطبعة العاشرة. 
Johansson, E. (2010), Can lean be mean? A study of negative consequences of lean in supply chains, unpublished Master Thesis, Blekinge School of Management.

Kakouris A., Finos P., Mihiotis A., 2015, Leading logistics dynamics to cost -efficient management , "East -West Journal of Economics and Business", 18(1).

Kumar, N. \& Bharathi, P. 2011, Continuous supply chain collaboration: Road to achieve operational excellence, Management Science Letters, Vol (1) .

Law L., 2016, An exploratory study of vendor logistics performance measurement for logistics management in Asia's apparel industry, Ph.D. thesis, Southern Cross University.

Lora Cecere, L. \& Mayer, A. 2013, What Drives Supply Chain Excellence? www.supplychaininsights.com

Macharia, A., 2014, Lean procurement and supply chain performance at Safari com limited , unpublished Master Thesis, University of Nairobi.

Mahfouz, A., 2011, An Integrated Framework to Assess 'Leanness' Performance in Distribution Centres. Ph.D. thesis, Dublin Institute of Technology, Dublin.

Manzini, R., 2012, Warehousing in the Global Supply Chain: Advanced Models, Tools and Applications for Storage Systems, SpringerVerlag London Limited.

Meera, L., Chitramani,P., Causal Effect of Between Lean and Green Supply Chain Management Practices on Environmental Performance of Manufacturing Firms, international journal of management \& business studies,6(2).

Mentzer J., Daniel J., Tomas M., 2001, Logistics Service Quality as a Segment-Customized Process, "Journal of Marketing", 65 (1).

Myerson, P. (2012). Lean supply chain and logistics management. McGraw-Hill.

Nimeh, H., Abdallah, H., and Sweis, R., 2017, Lean Supply Chain Management Practices and Performance: Empirical Evidence from Manufacturing Companies, International Journal of Supply Chain Management, Vol 7 (1).

Okeduo N., 2012, The Impact of Human Resources Management in Logistic Service Providers and Supply Chain Capabilities: A Case Study, "British Journal of Science", 4(1).

Oko A., 2016, Lean Supply Chain Management; Its Prospect for a Depressed Economy Like Nigeria, "International Journal of Advanced Engineering, Management and Science", 2(12).

Othman, A., Sundram, V., Sayuti, N., and Bahrin, A., The Relationship between Supply Chain Integration, Just-In-Time and Logistics Performance: A Supplier's Perspective on the Automotive Industry in Malaysia, International Journal of Supply Chain Management, 5(1).

Ozalp, I ., Suvacl , B., and Touns , H, 2012, A new approach in Logistic Management: Just in time logistic(JIT-L), International Journal of Business and Management Studies, 2( 1).
Cudney E., Elrod C., 2011, A comparative analysis of integrating lean concepts into supply chain management in manufacturing and service industries, "International Journal of Lean Six Sigma", 2 (1).

Czarnecka A ., Butor A., Halemba M., 2017, Lean supply chain management, "Journal of World Scientific News", 72.

Daud A., Zailani S., 2011, Lean Supply Chain Practices and Performance in the Context of Malaysia , Pathways for Research and Practice. www.intechopen.com

Daud,A. 2010, A Study on lean supply chain implantation in Malaysia's Electronical and Electrical Industry: practices and performance, unpublished Master Thesis .

Deji W., 2013, The role of excellence strategy to improving organization's performance, unpublished MBA project, MKU - Biskra.

Dharmapriya, S., Kulatunga, K., 2011, New Strategy for Warehouse Optimization - Lean warehousing, Proceedings of the 2011 International Conference on Industrial Engineering and Operations Management, Kuala Lumpur, Malaysia, January 22 - 24, 2011.

Drost E.A., 2011, Validity and Reliability in Social Science Research, "Education Research and Perspectives", 38(1).

Edres T., 2016, Efficiency and Quality of logistics services, first ed, Cairo University Library.

Farah M., 2015, Lean Supply Chain Management Practices and organization performance in the public water sector in Kenya. unpublished Master Thesis, University of Nairobi .

Gadde, L., Snehota, I.,2000, Making the Most of Supplier Relationships, Industrial Marketing Management, 29.

Gergova, I., 2010, Warehouse Improvement with Lean 5S - A Case Study of Ulstein Verft AS, unpublished Master Thesis, Molde University.

Ghiani, G. Laporte, G. Musmanno, R. 2013. Introduction to logistics systems management. 2nd Edition. John Wiley \& Sons, Ltd

Glatzel, C. \& Niemeyer, A. 2015, Excellence in Supply Chain https://www.mckinsey.com .

Gnich, S., 2012, Lean transportation: Applying Lean Thinking Basics to Transportation, unpublished Master Thesis, Copenhagen Business School.

Groznik A., Xiong Y, 2012, Pathways to supply chain Excellence, First published, Croatia. www.intechopen.com.

Hagstrom, M., Wollner ,M., 2011, Implementing Lean Procurement Opportunities, methods and hinders for medium sized enterprises - a case study, unpublished Master Thesis, Jonkoping University.

Hezbon K., 2016, Lean Supply Chain Management and Operational Performance of Almasi Beverages Company limited, unpublished MBA project, University of Nairobi .

Isikli N., 2013, The Impact of global trade on our daily lives. www.morethanshipping.com 
Tortorella L., Miorando. F., Fries E., 2017, Lean Supply Chain: empirical research on practices and performance, Proceedings of the International Conference on Industrial Engineering and Operations Management Rabat, Morocco, April.

Tostar, M., Karlsson, P., 2008, Lean Warehousing, Gaining from Lean thinking in Warehousing, unpublished Master Thesis, Lund University.

Ugochukwu P., 2012, Lean in the supply chain: research and practice. unpublished Master Thesis, Department of Management and Engineering, Linkopings University.

Villarreal , B., Garza-Reyes, J., and Kumar, V., 2016, Lean road transportation a systematic method for the improvement of road transport operations, Production Planning \& Control. http://dx.doi.org/10.1080/09537287.2016.11524 $\underline{05}$

Wachuma p., Shalle N., 2016, Effect of Lean Supply Chain Management Practices on Organizational Performance in Government Ministries in Kenya, "International Journal of Academic Research in Business and Social Sciences", 6(5).

Wee H., Wu S., 2009, Lean supply chain and its effect on product cost and quality: a case study on Ford Motor Company, "Supply Chain Management: An International Journal", 14(5).

Wilson, M., \& Roy, R. (2009). Enabling lean procurement: a consolidation model for smalland medium sized enterprises. Journal of manufacturing technology manage-ment, 20(6), 817-833.

Wirtz J., Heracleous L., Pangarkar N., 2008, Managing human resources for service excellence and cost effectiveness at Singapore Airlines, "Managing Service Quality ", 18(1).

Wodalski . J., Thompson.P, and Hanna.S, 2011, Applying Lean Techniques in the Delivery of Transportation Infrastructure Construction Projects, Construction and Materials Support Center, University of Wisconsin - Madison.

Wojtynek, L., Kulinska, E., Gruszka, M., and Kulińska, K., 2018, Implementation of lean 5S methodology in logistic enterprise, Research in Logistics \& Production, 8(2).

World Bank., 2014 , Connecting to Compete, The Logistics Performance Index and Its Indicators Report, www.worldbank.org

World Bank., 2017 , Logistics Competencies, Skills, and Training Report, www.worldbank.org .
Pettersson A., 2015, Measurement of Excellence and Cost in a Supply Chain, Ph.D. thesis, Lulea University of Technology.

Rachid B., Roland D., Sebastien., D., Ivana R., 2017, Risk Management Approach for Lean, Agile, Resilient and Green Supply Chain, "International Journal of Social, Behavioral, Educational, Economic, Business and Industrial Engineering”, 11(4).

Reddy, R., Raju, I., Reddy, D., and Krishnaiah, G., 2016, Lean Supplier Selection based on Hybrid MCGDM Approach using Interval Valued Neutrosophic Sets: A Case Study, international journal of innovative research \& development, 5(4).

Robinson A., 2018, Using multi-item psychometric scales for research and practice in human resource management, "Human Resource Management", Special Issue.

Rossini, M., Studacher,A., 2015, Simulation of Lean Principles Impact in a Multi-Product Supply Chain, International Journal of Social, Behavioral, Educational, Economic, Business and Industrial Engineering, 9(11).

Sezen B., Erdogan S., 2009, Lean Philosophy in strategic Supply Chain Management and Value Creating," journal of global strategic management", 3 (1).

Slack N., Chambers S., Johnston R. , 2010, Operation Management. 6th edition, prentice Hall.

Sobanski, E.B., (2009), Assessing Lean Warehousing: Development and Validation of a Lean Assessment Tool, Ph.D. thesis, July, 2009, Oklahoma State University, Stillwater, Oklahoma.

Swart, E., 2015, The current understanding of the lean warehousing principal to provide resources in a third party logistics provider in South Africa, unpublished Master Thesis, University of the Witwatersrand, Johannesburg.

Taylor, L. Martichenko, R.,2006, Lean TransportationFact or Fiction?. Executive White Paper, Fedex, September, Memphis, TN.

Thuranira, M., 2016, The effect of supply chain management components on operational performance among tea factories in Kenya, unpublished Master Thesis, University of Nairobi.

Tompkins, Bruce (2010), "Lean Thinking for the Supply Chain", Tompkins Associates, USA. 


\section{الملحق (1) استمارة الاستبيان \\ م/ ماستمارة الاستبيان}

حضرة السيد المجيب على الاستمارة المحترم . ..... تحية طيبة

تمثل هذه الاستمارة جزء من مشروع اطروحة دكتوراه في ادارة الاعمال والموسومة " دود بعض أنشطة ادارة سلسلة التوريد الرثيقة في تحقيق

$$
\text { التميز اللوجستي : دراسة استطلاعية " }
$$

وتعد هذه الاسـتمارة مقياسـاً يعتمد عليه لأغراض البحث العلمي حصـراً ولا تسـتخدم لتفسـير نواحي الخلل في عمل شـركتكم الموقرة. لذا تعد

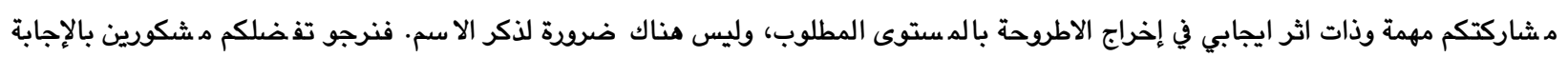
ووضع علامة ( ل) أمام الاختيار الذي تراه منا سبا" لكل سؤال. وسنكون شاكرين بالإجابة على جميع الاسئلة لان ترك اي سؤال بدون إجابة يعني عدم صلاحية الاستمارة للتحليل. واذا كان هناك صعوية في فهم اي سؤال او فقرة سيكون الباحث سعيداً جداً لتوضيحها لكم . شكراً على وقتكم مع التقدير الباء سيد

الباحث

$$
\text { المشرف }
$$

م.فرست علي شعبان بوتي

البروفيسور د.خيري علي اوسو

أولا: البيانات خاصة عن المجيبين :

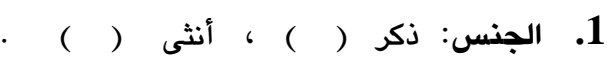

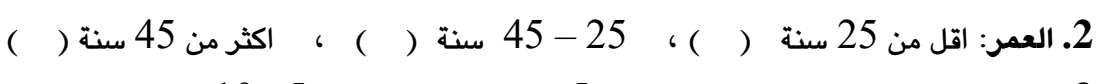

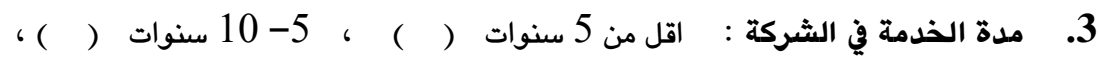

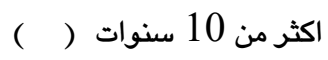

4. التحصيل الدراسي: اعدادية فما دون ( ) ، دبلوم فني ( ) ، بكالوريوس ( ) ، شهادة عليا ( ).

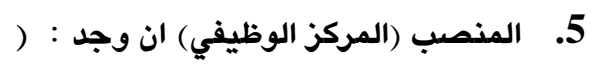

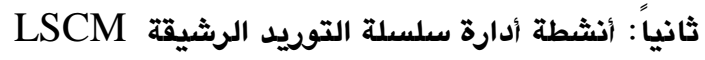
مجموعة من الأنشطة التي تتدفق من خلالها المواد والمنتجات بسلاسة عبر ادارة سلسلة التوريد الرشيقة مع عدم وجود اي هدر فيها لمقابلة متطلبات الزيائن وتحقيق القيمة المضافة. الهدر: تعني الضياعات او النفايات او الوقت الزائد او الانشطة الزائدة التي لا تضيف قيمة. الرشاقة: تعني التقليل من استخدام الموارد وعدم التبذير فيها. وتتكون LSCM من الانشطة الاتية :

Lean Purchasing الشراء الرشيق نشاط يركز على ادراك ومعرفة احتياجات العملية الانتاجية المستندة على متطلبات الزبائن ونقلها للموردين لتوفيرها دون توليد اي انواع من الهدر،

\begin{tabular}{|c|c|c|c|c|c|c|}
\hline لا اتفق & اتفق & 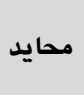 & 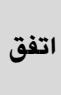 & بشدة اتفق & 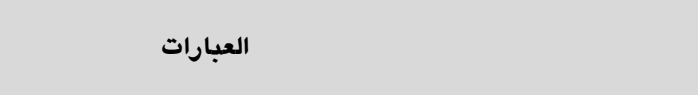 & ت \\
\hline & & & & & يمتاز نشاط الشراء في شركتنا بالمرونة ويلبي جميع انواع الطلب . & V1 \\
\hline & & & & & يهتم نشاط الشراء في شركتنا بتوفير مواد مطابقة لمتطلبات الزبائن. & $\mathrm{V} 2$ \\
\hline & & & & & تجتهد شركتنا باستخدام الشراء الالكتروني لتوفير احتياجاتها من المواد. & V3 \\
\hline & & & & & تهتم شركتنا بمعالجة جميع انواع الهدر في نشاط الشراء. & V4 \\
\hline
\end{tabular}
وتعتمد بعض عمليات الشراء الرشيق على الشراء الالكتروني المستند على شبكة الانترنيت. 


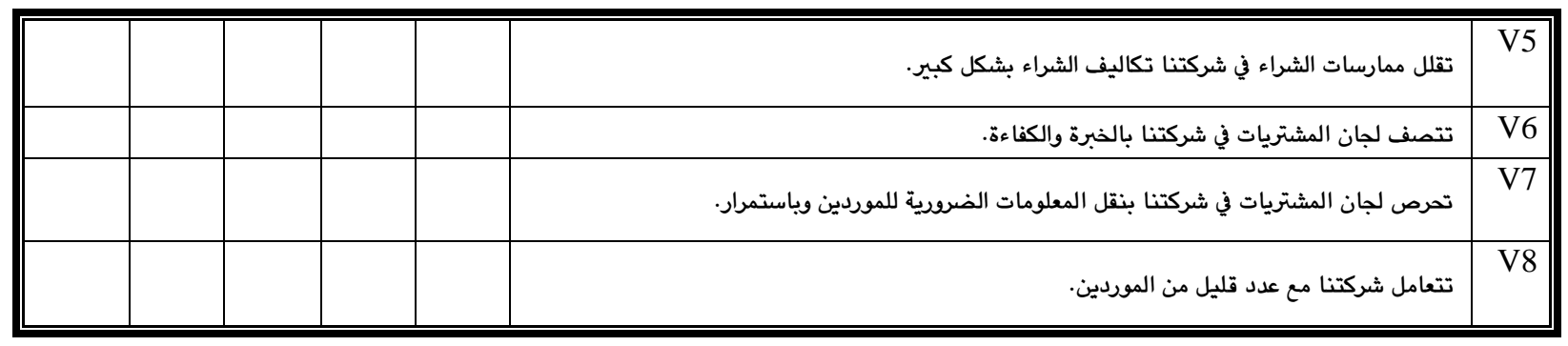

2. النقل الرشيق Lean Transportation نقل المواد والمنتجات في الوقت والمكان المحددين بالجودة والكمية المطلوية ويالاعتماد على مفاهيم الرشاقة في عمليات النقل بالتخلص من جميع انواع الهدر فيها والاعتماد على مبدأ السحب لخفض التكاليف النقل.

\begin{tabular}{|c|c|c|c|c|c|c|}
\hline ل ا ل اتفق & لا لاتفق & 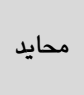 & اتفق & بشدة & 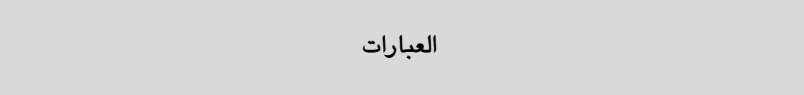 & $ت$ \\
\hline & & & & & تدرك شركتنا بان نشاط النقل من اكثر الانشطة التي تضيف قيمة للزبائن. & V9 \\
\hline & & & & & تعالج شركتنا جميع انواع الهدر في نشاط النقل. & V10 \\
\hline & & & & & تستخدم شركتنا ممارسات تهدف الى خدمة الزبون في مجال النقل. & V11 \\
\hline & & & & & تستخدم شركتنا وسائل نقل مناسبة تناسب طبيعة اسواقها. & V12 \\
\hline & & & & & ساهم خفض كلف النقل في شركتنا من تعزيز مركزها التنافسي. & V13 \\
\hline & & & & & تستخدم شركتنا التوريد في الوقت المناسب بهدف تقليل المسافات المقطوعة والاوقات & V14 \\
\hline & & & & & تمتلك شركتنا المورد البشري المناسب والكفوء لإدارة نشاط النقل. & V15 \\
\hline & & & & & تتم عمليات النقل في شركتنا بالاعتماد على معلومات موثقة ودقيقة. & V16 \\
\hline
\end{tabular}

Lean Warehousing التخزين الرشيق نشاط تسعى لتحسين عمليات التخزين من خلال التخلص من جميع انواع الهدر فيها مثل: زيادة فترة الانتظار تصريف الانواع الخاطئة والزيادة في مستويات المخزون، ويسعى المفهوم من استخدام ادوات ترفع من كفاءة العمليات المخزنية.

\begin{tabular}{|c|c|c|c|c|c|c|}
\hline لا اتفق & لا اتفق & محايد & اتفق & بشدة اتفق & 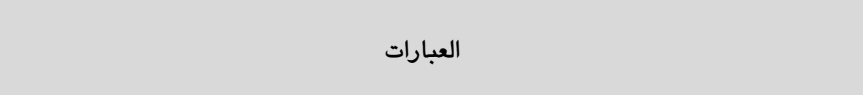 & ت \\
\hline & & & & & تتبع شركتنا اجراءات مخزنية تسهل من عمل الانشطة اللوجستية. & V17 \\
\hline & & & & & تهدف ادارة المخازن في شركتنا التخلص من جميع انواع الهدر في العمليات المخزنية. & V18 \\
\hline & & & & & تُسهل اجراءات التخزين في شركتنا عمل الموردين. & V19 \\
\hline & & & & & توجه العمليات المخزنية في شركتنا لذدمة الزيون . & V20 \\
\hline & & & & & يمتاز عاملوا المخازن في شركتنا بالخبرة المطلوية . & V21 \\
\hline & & & & & تتم عمليات السحب من مخازن الشركة في حال وجود طلبيات حقيقة باعتماد مبدأ السحب. & V22 \\
\hline & & & & & توفر شركتنا معلومات عن مستويات الخزين للمواد المخزونة للجهات ذات العلاقة باستمراد . & V23 \\
\hline & & & & & يسهم نظام المعلومات المخزنية في الشركة على تجنب حدوث اخطاء مخزنية . & V24 \\
\hline
\end{tabular}


ثالثا: التميز اللوجستي: يتمثل مجال التركيز الاساسي للتميز اللوجستي في تحقيق مستويات عالية من الجودة والانتاجية للأعمال اللوجستية، وتحقق الشركة التميز اللوجستي من خلال قدرتها على اقامة المتطلبات الاتية :(التركيز على الزيون ، تقليل الكلف عبر تحسين العمليات اللوجستية، العلاقة مع الموردين، مورد بشري مناسب، نظام معلوماتي متقدم).

\begin{tabular}{|c|c|c|c|c|c|c|}
\hline 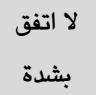 & لا اتفق & محايد & اتفق & 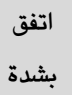 & التميز اللوجستي & \\
\hline & & & & & تدرك شركتنا بان احدى متطلبات تحقيق التميز اللوجستي هي الايفاء بمتطلبات الزبائن. & V25 \\
\hline & & & & & ترى شركتنا بان التركيز على الزبون وفهم متطلباته يسهم في تحسين جودة الذدمة اللوجستية. & V26 \\
\hline & & & & & طورت شركتنا انشطتها اللوجستية بحيث تكون مصممة خصيصاً لتلبية متطلبات الزبائن. & V27 \\
\hline & & & & & 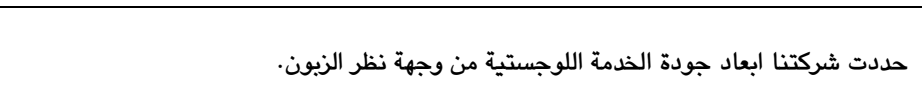 & V28 \\
\hline & & & & & تلدرك شركتنا بان تحسين العمليات اللوجستية لذفض الكلف تعد من المتطلبات لتحقيق التميز & V29 \\
\hline & & & & & يسهم تطوير قدرات الشركة اللوجستية في تحقيق التميز اللوجستي. & V30 \\
\hline & & & & & تراعي شركتنا في تصميم شبكة اللوجستيات معايير الخدمة المقدمة لتحقيق التميز فيها. & V31 \\
\hline & & & & & لدى شركتنا المرونة في ادارة خدماتها اللوجستية مع حالات عدم التأكد البيئي. & V32 \\
\hline & & & & & تلجأ شركتنا الى الشراكة والعلاقة التبادلية مع الموردين بهدف تحقيق التميز اللوجستي. & V33 \\
\hline & & & & & تبني شركتنا علاقتها مع الموردين لفترات طويلة. & V34 \\
\hline & & & & & تتميز العلاقة بين شركتنا ومورديها بالثقة المتبادلة. & V35 \\
\hline & & & & & تدرك شركتنا بان تحقيق التميز اللوجستي لا يتحقق بدون وجود تعاون وثيق بينها وبين مورديها & V36 \\
\hline & & & & & تمتاز شركتنا بإدارة أعمالها اللوجستية عن طريق فرق عمل لوجستية متميزة & V37 \\
\hline & & & & & يعطي المدراء اللوجستيك في شركتنا اهمية لعمال اللوجستيك لتأثيرمم في تحقيق التميز. & V38 \\
\hline & & & & & يشرك المدراء اللوجستيك في شركتنا عمال اللوجستيك في وضع الخطط المتعلقة بالأنشطة & V39 \\
\hline & & & & & تمتلك شركتنا عاملين يمتازون بالخبرة في مجال إدارة الانشطة اللوجستية. & V40 \\
\hline & & & & & تطبق شركتنا نظام معلومات متطور لإدارة انشطتها اللوجستية. & V41 \\
\hline & & & & & تدرك شركتنا اهمية نظام المعلومات في تحقيق التميز اللوجستي . & V42 \\
\hline & & & & & سهل نظام المعلومات المتبع في شركتنا اداء الانشطة اللوجستية. & V43 \\
\hline & & & & & العلاقة. & V44 \\
\hline
\end{tabular}




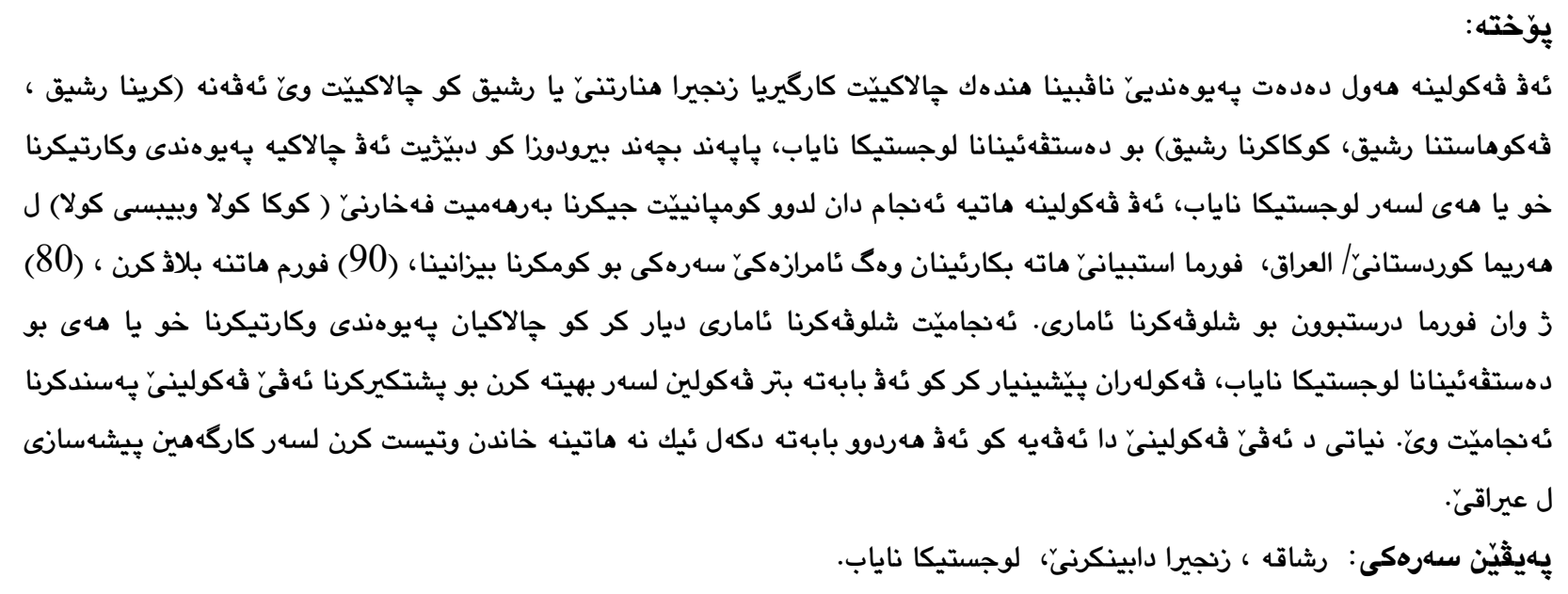

\title{
The Role of some Activities of Lean Supply Chain Management (LSCM) in Achieving Logistics Excellence \\ "Exploratory study"
}

\begin{abstract}
:
The study tries to determine the relationship between some activities of Lean supply chain management (lean procurement, lean transport, and lean storage) in achieving Logistics Excellence. Based on a set of hypotheses that states that these activities are related and affect the Logistics Excellence, the study was applied on two Companies (Coca-Cola and Pepsi Cola) for the production of beverages in the Kurdistan region / Iraq. The questionnaire was used as a main tool for data collection, (90) questionnaire were distributed to supply chain managers, logistics and first line managers, (80) of them were return and were valid for analysis, use correlation and affect tests to verify hypotheses. The results of the statistical analysis supported the hypotheses of the study and indicated the existence of correlation and affect of the lean supply chain activities in Logistics Excellence, the researchers propose further studies in the future on the subject to support and enhance the results of this study. The contribution of the current study comes from the support of the researched companies for benefiting from the idea and the results of the study for which the study of variables has not previously been studied in the Iraqi manufacturing environment according to researchers' knowledge.
\end{abstract}

Keywords: Lean, Supply Chain, Logistics Excellence. $\square$ 